\title{
Mechanisms of Stability of Armored Bubbles: FY 1995 Progress Report
}

April 1996

Prepared by the University of Texas at Austin for Pacific Northwest Nátional Laboratory Under Contract DE-AC06-76RLO 1830

Pacific Northwest National Laboratory Operated for the U.S. Department of Energy by Battelle

\section{Battelle}




\section{DISCIAIMER}

This report was prepared as an account of work sponsored by an agency of the United States Government. Neither the United States Govemment nor any agen'cy thereof, nor Battelle Memorial Institute, nor any of their employees, makes any warranty, express or implied, or assumes any legal liability or responsibility for the accuracy, completeness, or usefulness of any information, apparatus, product, or process disclosed, or represents that its use would not infringe privately owned rights. Reference herein to any specific commercial product, process, or service by trade name, trademark, manufacturer, or othenwise does not necessarily constitute or imply its endorsement, recommendation, or favoring by the United States Government or any agency thereof, or Battelle Memorial Institute. The views and opinions of authors expressed herein do not necessarily state or reflect those of the United States Government or any agency thereof.

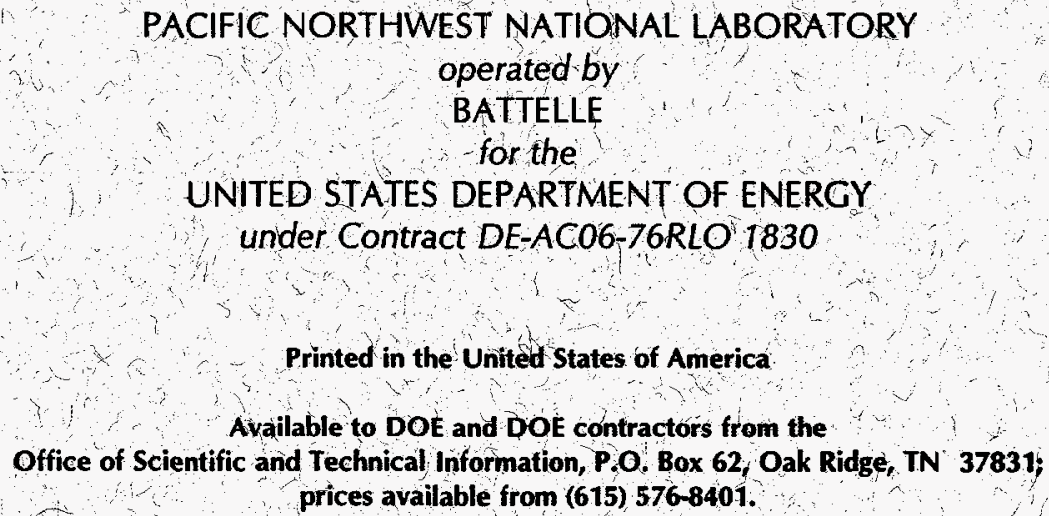

Printed in the United States of America

Available to DOE and DOE contractors from the Office of Scientific and Technical Information, P.O. Box 62, Oak Ridge, TN 37831; prices available from (615) $576-8401$.

Available to the public from the National Technical Information Service, U.S. Department of Commerce, 5285 Port Royal Rd, Springfield, VA 22161 
PNNL-11133

UC-2030

\section{Mechanisms of Stability of Armored Bubbles: FY 1995 Progress Report}

W. R. Rossen

S. K. Das

April 1996

Prepared by the Department of Petroleum and Geosystems Engineering The University of Texas at Austin for Pacific Northwest National Laboratory under Contract DE-AC06-76RLO 1830 and Agreement 283947-A-I3

Pacific Northwest National Laboratory

Richland, Washington 99352 



\section{Contents}

Summary

Introduction $\quad \cdots 1$

$\begin{array}{ll}\text { Objectives } & 2\end{array}$

$\begin{array}{ll}\text { Approach } & 2\end{array}$

$\begin{array}{ll}\text { Experiments } & 2\end{array}$

$\begin{array}{ll}\text { Preparation of Synthetic Waste } & 3\end{array}$

Interfacial Dilational Properties $\quad 5$

$\begin{array}{ll}\text { Theory } & 6\end{array}$

Results and Discussion $\quad$ - 12

$\begin{array}{ll}\text { Experiments } & 12\end{array}$

Bubble Stabilization by Solids in Synthetic Hanford Waste 12

$\begin{array}{ll}\text { Interfacial Dilational Properties } & 16\end{array}$

$\begin{array}{ll}\text { Theory } & 23\end{array}$

$\begin{array}{ll}\text { Conclusions } & 24\end{array}$

$\begin{array}{ll}\text { References } & 25\end{array}$ 


\section{Figures}

1 Schematic of the pulse drop interfacial rheometer

2 Geometry of two-dimensional liquid film between two bubbles stabilized by solid cylindrical particles

3 Capillary force pulling two solid cylinders together

4 Dilational properties of simulant/air interface containing no EDTA and with no solid particles deliberately added to the gas-liquid interface

$5 \quad$ Dilational properties of simulant-air interface containing $0.05 \mathrm{M}$ EDTA with not solid particles deliberately added to the interface

6 Dilational properties of simulant-air interface containing $0.1 \mathrm{M}$ EDTA with no solid particles deliberately added to the interface

7 Dilational properties of simulant-air interface containing $0.17 \mathrm{M}$ EDTA with no solid particles deliberately added to the interface

8 Dilational properties of simulant-air interface containing $0.1 \mathrm{M}$ EDTA with solid particles deliberately added to the interface

9 Dilational properties of simulant-air interface containing

$0.17 \mathrm{M}$ EDTA with solid particles deliberately added to the interface

10 Effect of EDTA concentration on the limiting values of dilational elasticity

11 Variation of dilational viscosity with EDTA concentration

12 Effect of EDTA concentration and solid particles deliberately added to the interface on the characteristic relaxation time

13a Limit of stability for films (Criterion 1) for $\theta=0$

$13 b$ Limit of stability for films (Criterion 1) for $\theta=0$ 
14 Limit of stability for films (Criterion 3) with fixed volume (constant $\mathrm{V} / \mathrm{Rp}_{2}$ ) for $\theta=0$

15 Limit of stability for films (Criterion 3) with fixed capillary pressure (constant $\mathrm{Rp} / \mathrm{R} 1$ ) for $\theta=0$

16 Limit of stability for films (Criterion 3) with fixed volume for $\theta=0$

17a Limit of stability for films (Criterion 1) for $\theta=25$

17b Limit of stability for films (Criterion 1) for $\theta=25$

18 Limit of stability for films (Criterion 3 ) with fixed volume (constant $\mathrm{V} / \mathrm{Rp}^{2}$ ) for $\theta=25$

19 Limit of stability for films (Criterion 3) with fixed capillary pressure (constant $\mathrm{Rp} / \mathrm{R} 1$ ) for $\theta=25$

20 Limit of stability for films (Criterion 3 ) with fixed volume for $\theta=25$

\section{Tables}

1 Synthetic Waste Formulation 

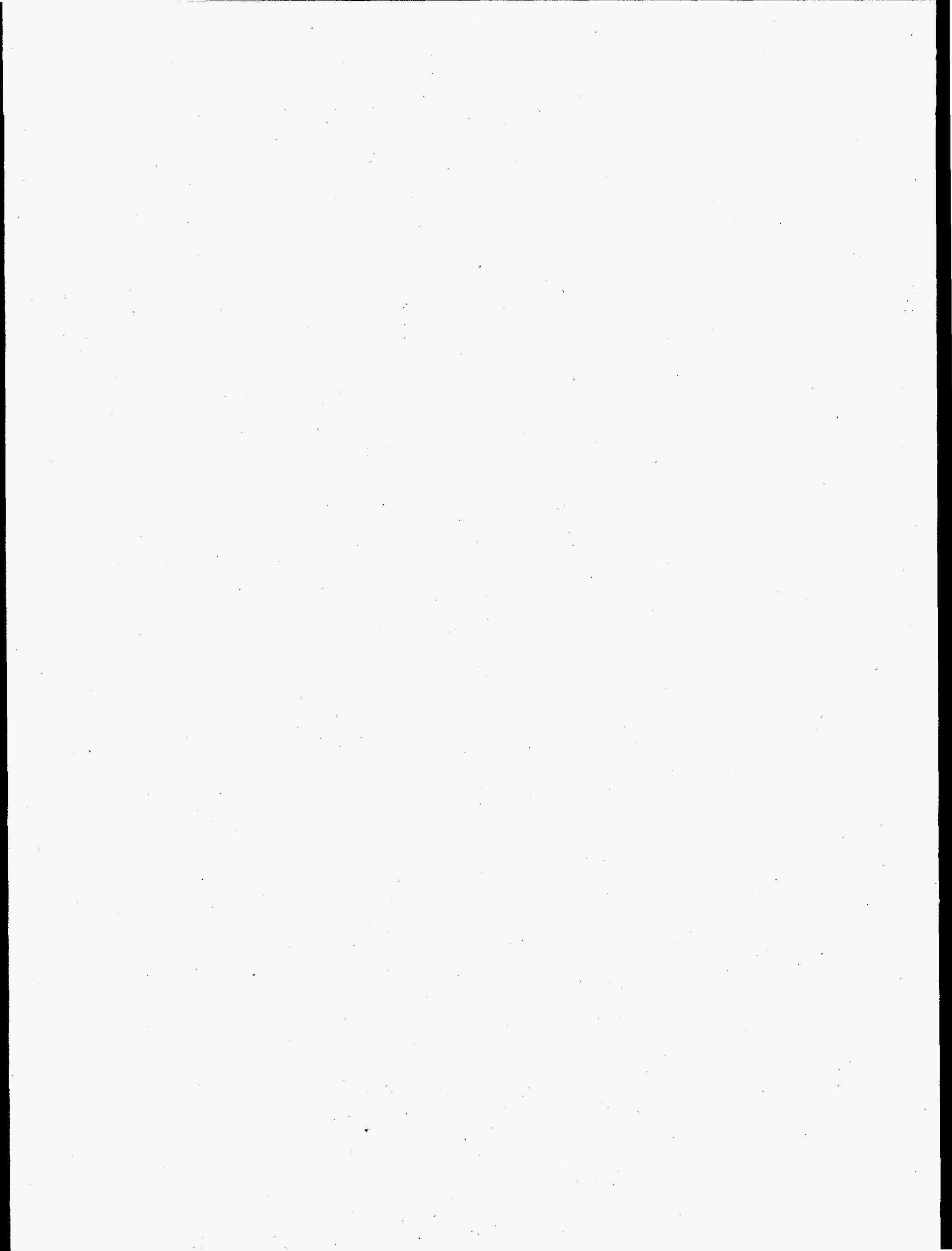


\section{SUMMARY}

Experimental and theoretical studies of stabilization of liquid films between bubbles were undertaken as part of an effort to model gas release in waste tanks at the Hanford nuclear reservation. Synthetic Hanford waste created here showed solids accumulation at bubble surfaces and some stabilization of bubbles in a froth upon sparging with nitrogen. Dilational interfacial rheological measurements indicate increasing hydrophobicity with increasing EDTA concentration in the wastes. There is greater dilational elasticity of the interface with solid particles present on the interface: Theoretical modeling of a $2 \mathrm{D}$ liquid film between bubbles containing one row of solid particles suggests that in 3D such a film would be unstable unless the solids all touch. This hints at a possible mechanism for bubble stabilization, if it can be argued that slowly evolving interfaces, as bubbles grow toward each other in the sludge, have solids closely packed, but that rapid expansion of gas during a rollover event forces the films to expand without additional solids.

\section{INTRODUCTION}

Concern about gas discharges from waste tanks at the Hanford nuclear reservation has led to study of the mechanisms by which gas is trapped in and then catastrophically released from the sludge at the bottom of these tanks (1). It appears that gas evolving within the sludge over a period of months is trapped by solid particles until the density of the sludge falls below that of the liquid above it. The sludge rises, reducing the hydrostatic pressure on its trapped gas, and as a result this gas expands by a factor of two or three. Sometime during this expansion period most of the gas is released. If this picture is correct, then the trigger for the release of gas is either (a) gas volume fraction exceeding some threshold value or (b) the relatively rapid increase in gas volume (over a matter of minutes or hours), in contrast to the slow accumulation of gas before the event.

One plausible mechanism of gas trapping within the sludge is stabilization of gas bubbles by solid particles accumulated on the surfaces of the bubbles. This mechanism is 
the basis of froth flotation, used to separate crushed mineral ores in the mining industry (2). The study described here focuses on experimental study of the accumulation of solids at the liquid-gas interface in simulated Hanford tank sludge and the effect of these solids on the interfacial rheology of the waste, and on theoretical study of the conditions under which solids can stabilize a film of liquid between bubbles.

\section{OB.JECTIVES}

The specific objectives of this study are as follows:

- Create simulated Hanford tank waste

- Observe accumulation of solids on bubbles surfaces in the waste and stabilization of these bubbles by these solids.

- Measure interfacial dilational properties of solids-laden surfaces between of simulated waste and gas.

- Develop a theory for the stabilization by solids of liquid films between bubbles.

\section{APPROACH}

\section{Experiments}

It is a well established fact that finely divided solid particles of colloidal dimensions play a significant role in stabilizing liquid-liquid emulsions (3-12). Stabilization occurs due to diffusion of these partially wet solid particles to the interface and formation of a rigid barrier that sterically prevents coalescence of the discontinuous phase. In addition, the presence of solid particles affects the interfacial rheological properties which in turn plays a significant role in the drainage of fluid from the thin liquid film between the approaching drops (or bubbles). A similar mechanism may be involved in stabilization of bubbles in Hanford tank waste. The main objective of this experimental study is to determine the possible role of fine salt crystals in stabilizing the gas bubbles and thereby preventing the formation of a continuous channel for the gas escape as it is generated in the sludge. These 
experiments employed synthetic waste containing different concentrations of organics.

\section{Preparation of Synthetic Waste}

The simulants, whose compositions are listed in Table 1 below, were prepared using the procedure similar to that used at PNL (13). They contained the major components listed in Table B11 of Ref. (13): sodium aluminate, sodium nitrate, sodium nitrite, sodium hydroxide, and sodium chloride. The other salts of sodium, i.e. phosphate, carbonate, and fluoride, and the nitrate salts of the transition metal ions, were not included, as the concentrations of these components listed in Table B11 are quite small. The concentrations of the various sodium salts used here were those of formulation SY1-SIM92A, listed as the PNL formulation in the Table B11 of Ref. (13), which showed formation of precipitate in that study. The formulations were similar to that of Westinghouse Hanford Company, listed in the same Table, except that it contained sodium carbonate and no HEDTA (13). The formulations are also roughly similar to those presented in Table 1 of Ref. (14). In our work, EDTA was varied systematically from 0 to $0.17 \mathrm{M}$, maintaining the molar ratio of HEDTA to EDTA constant at 2.06. Thus total organics concentration varied from 0 to $0.52 \mathrm{M}$. The organics are the only components thought to have any surface activity. All the samples were prepared by heating the mixture to about $90^{\circ} \mathrm{C}$ for about 10 to $12 \mathrm{hrs}$ and subsequently cooling it down to room temperature (about $25^{\circ} \mathrm{C}$ ). The gases generated during the process were not analyzed but vented, while any evaporated water was recycled through a condenser. After being set aside to settle for about 4 days each of the samples was sparged with dry nitrogen through a porous frit for about 30 seconds to observe the formation of any stable froth. The samples were analyzed under an optical microscope to observe the armoring of gas bubbles and to determine the approximate shape and size of the solid crystals. 


\section{TABLE 1}

Synthetic Waste Formulation

\begin{tabular}{lc} 
Component & $\begin{array}{c}\text { Concentration } \\
\text { (moles/liter) }\end{array}$ \\
\hline $\mathrm{NaAlO}_{2}$ & 2.1 \\
$\mathrm{NaCl}$ & 0.35 \\
$\mathrm{NaNO}_{2}$ & 3.1 \\
$\mathrm{NaNO}_{3}$ & 3.1 \\
$\mathrm{NaOH}$ & 2.9 \\
HEDTA/EDTA & 2.06 \\
\hline
\end{tabular}




\section{Interfacial Dilational Properties}

As mentioned earlier, the stability of an emulsion depends strongly on the rate of drainage of the continuous phase from the intervening film between the approaching bubbles. Film-thinning studies have shown that the rate of film drainage in turn is a strong function of interfacial-tension gradients, interfacial shear viscosity, and interfacial dilational viscosity (15). It has also been observed that when the interfaces are even slightly mobile, the rate of drainage can be several orders of magnitude greater than that for an immobile interface. In addition, research has shown that interfaces containing surface-active agents and/or colloidal particles exhibit viscoelastic behavior (13-17). This research shows that the dilational modulus, which is a measure of viscoelasticity, is the dominant parameter governing stability of crude-oil emulsions and foams compared to the effects of shear modulus or interfacial-tension gradients. The same studies show that when the interfacial layer exhibits both viscous and elastic properties, the mobility of this layer, and hence the stability of the emulsion, depends strongly on dilational elasticity of the interface.

A sudden change in the area of an interface can give rise to a sudden change in interfacial tension, due to lower surface coverage of surface-active particles or molecules. In the absence of any flow at the interface, this in turn gives rise to a surface pressure, which is defined as the difference between the interfacial tension before and after deformation. When this change in interfacial tension upon a change in area is accompanied by a relaxation mechanism, the interface exhibits viscoelastic behavior. These relaxation phenomena could arise from molecular reorientation at the interface and/or diffusion of surface-active molecules or solid particles along the interface or to and from the bulk fluid. The viscoelastic modulus can be defined only in the frequency domain because the change in interfacial tension due to change in area depends on the rate at which the change in area occurs (21). It is a complex function of frequency, the real part of which is the dilational elasticity and the imaginary part is proportional to the dilational viscosity. The complete frequency spectrum can be obtained from the Fourier transform of the dynamic interfacial 
tension data. For purely elastic interface any variation in interfacial tension due to area change is instantaneous and the elastic modulus is identical to equilibrium or Gibbs elasticity, independent of frequency.

In this study, dynamic interfacial-tension data were obtained using the pulse-drop interfacial rheometer developed at the University of Texas at Austin (22). The schematic of the apparatus is shown in Figure 1. The principal components of the apparatus are an ultralow-range $(0.125 \mathrm{psi})$ Validyne differential pressure transducer, a capillary tube $(0.066 \mathrm{~cm}$ ID), a microliter syringe, and a computerized data-acquisition system.

The procedure involves a sudden expansion of the gas-liquid interface at the end of the capillary. The initial shape of the interface is made flat by adjusting the amount of fluid in the capillary using the microsyringe so that the pressure differential read by the transducer is approximately zero. The expansion is then carried out by suddenly injecting a known volume of liquid so that the liquid forms a hemisphere at the tip of the capillary. The output from the pressure transducer is recorded at the rate of 10 data points per second over a period of about 20 to 30 seconds during which the reading reaches a steady equilibrium value. Data-acquisition software from National Instruments is used for this purpose. The above procedure was repeated at least five times for every sample of simulants. The average of these dynamic tension data were then analyzed with the help of a commercial digital signal processor for transformation into Fourier space.

In order to study the effects of solid particles, special care had to be taken to ensure their presence at the interface. In some cases, this was accomplished by carefully placing a small amount of liquid containing the particles in suspension at the end of the capillary tube with the help of a microliter syringe. These experiments were also repeated at least five times for each sample and their average analyzed.

\section{Theory}

The objective of our theoretical work is to determine under what conditions solids 


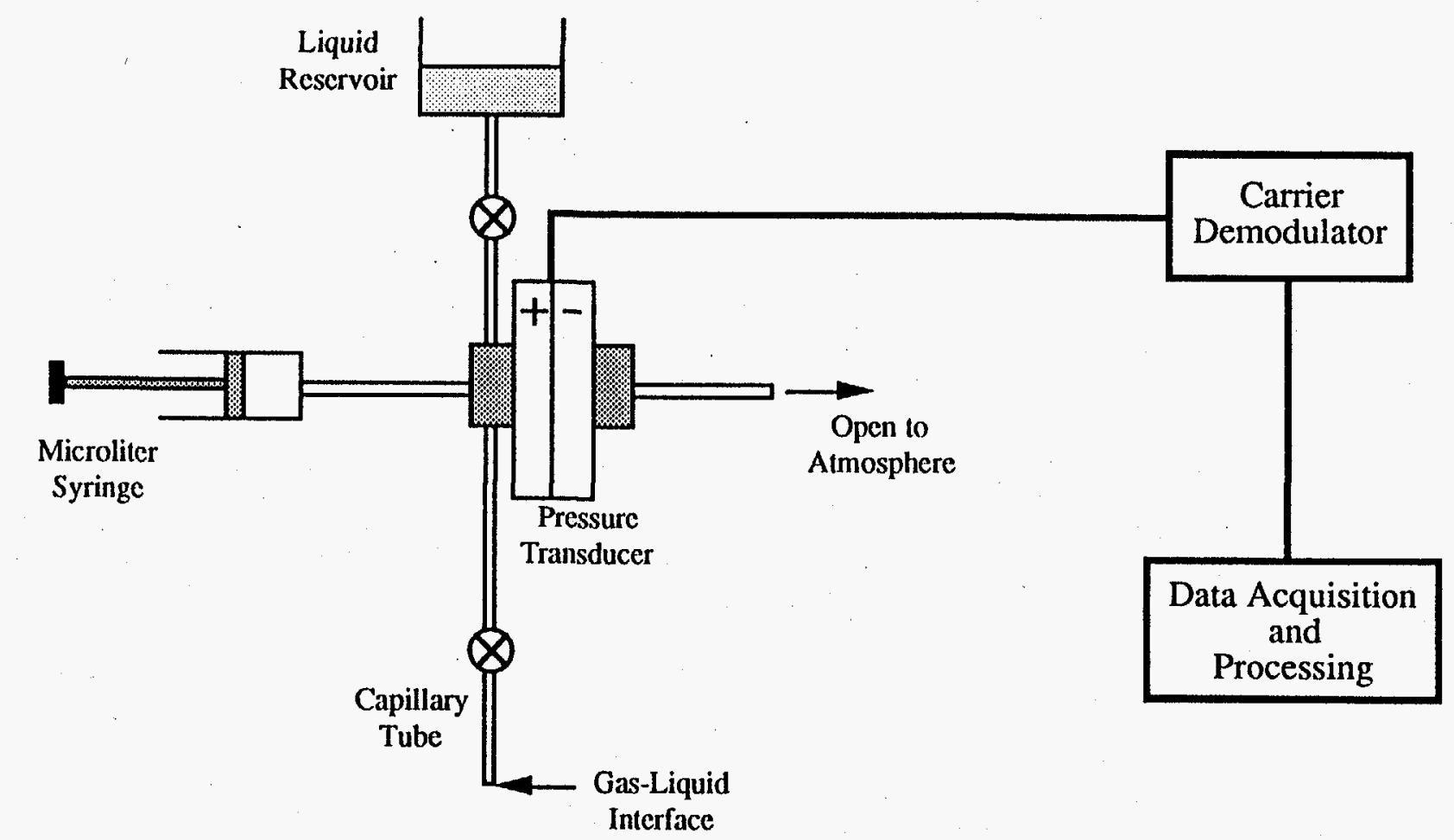

Fig. 1. Schematic of the pulse drop interfacial rheometer. 
can stabilize a film of liquid separating two gas bubbles that would rupture in the absence of the solids. The determination of the arrangement of solids of a variety of sizes and shapes and the geometry of the liquid-gas interfaces in such a film in there dimensions is extremely complex. Our approach is similar to that of Frye and Berg (23) and Levine and Bowen (24). To simplify the problem for initial study, we made the following assumptions:

- Two-dimensional (2D) geometry. In other words, the solids are cylinders arranged perpendicular to the plane of view. Figure 2 illustrates the arrangement assumed for the special case of liquid completely wetting the solid cylinders. The approach is'similar, though the formulas are more complex, for cases of finite contact angle, which are also included below.

- If the two opposing liquid-gas surfaces between any pair of cylinders touch, the film ruptures.

- The cylinders have identical radius $R_{p}$, although they need not be equally spaced along the film.

- There is only one row of cylinders within the film.

- The film is planar - i.e., the centers of the cylinders lie on a single plane. Contact angle $\theta$ need not be zero, although for simplicity that case is shown in Figures 2 and 3.

- The contact angle of liquid on the solids is the same everywhere. There is no contact-angle hysteresis.

- Gravity plays an insignificant role in fluid distribution on the length scale of the distance between individual particles.

With these assumptions, determining the geometry of liquid and solids arrangement on the film and the film's stability is an exercise in planar geometry. Figure 2 shows the definitions of geometrical parameters involved in this problem. Two of these parameters together uniquely determine all the others. Computationally, it is convenient to use as 


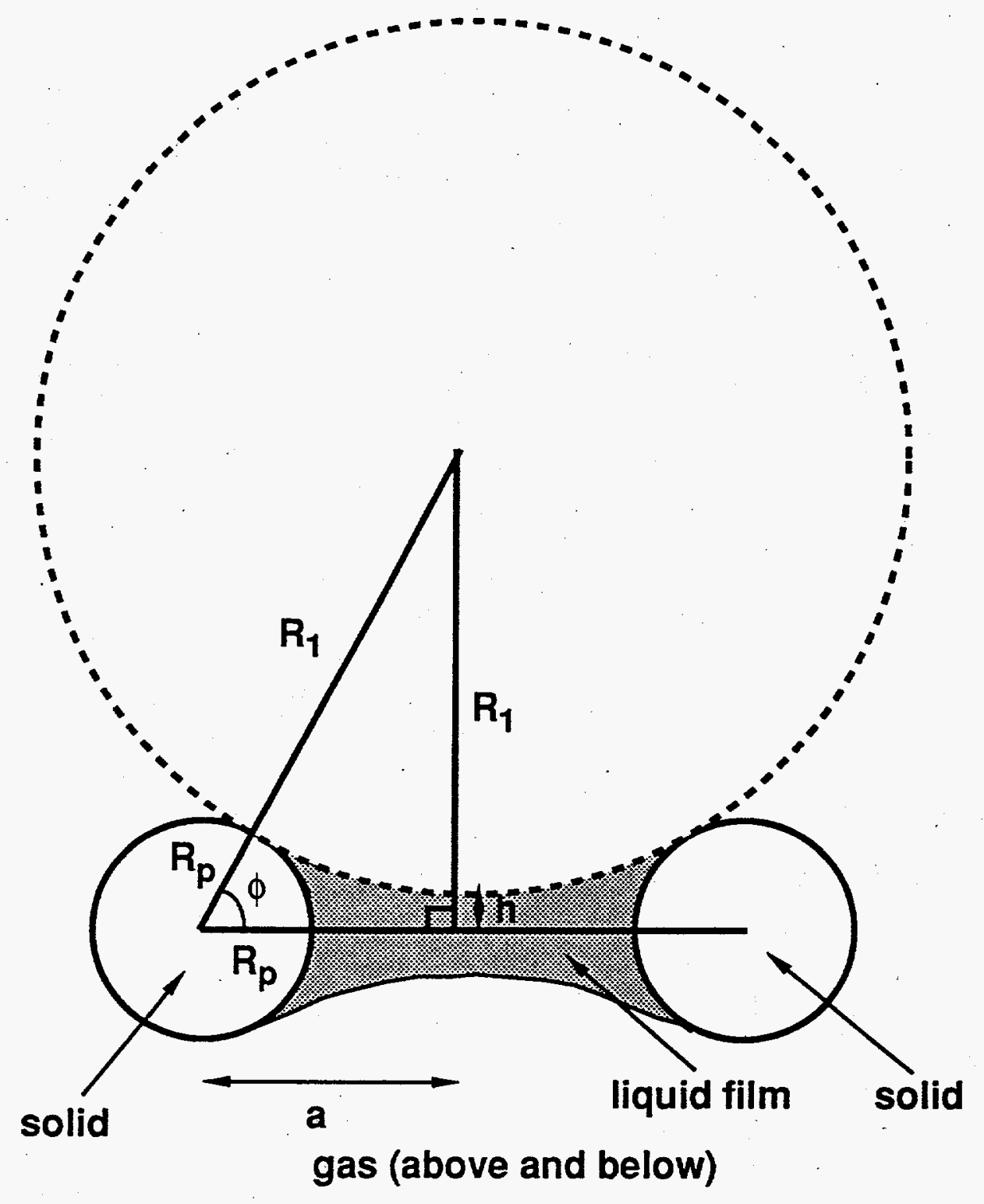

$$
\begin{aligned}
& \mathbf{Q} \equiv \mathbf{a} / \mathbf{R}_{\mathrm{p}} \\
& \mathbf{P}_{c}=\left(\gamma / \mathbf{R}_{\mathrm{p}}\right) /\left(\mathbf{R}_{\mathbf{1}} / \mathbf{R}_{\mathrm{p}}\right)
\end{aligned}
$$

Fig. 2. Geometry of two-dimensional liquid film between two bubbles stabilized by solid cylindrical particles 
independent parameters $\phi$, the angle of a ray from the center of the cylindrical solid to the liquid-gas contact line on the cylinder, and $Q \equiv a / R_{p}$, the ratio of the distance between centers of solids ( 2 a) to the diameter of one cylinder $\left(2 R_{p}\right)$. From these one can determine

- F, the force drawing the two cylinders together. This force has two components: first, surface tension acting at the points of contact of liquid with a cylinder; and, second, pressure, specifically, the lower pressure in the liquid than gas, acting normal to the surface of cylinder everywhere it is in contact with liquid. Figure 3 illustrates these two forces for the special case of liquid completely wetting the solid cylinders $(\theta=0)$. The approach is similar, though the formulas are more complex, for cases of finite contact angle.

- $R_{1} / R_{p}$, the ratio of radius of the liquid-gas surface to cylinder radius. This ratio is inversely proportional to capillary pressure $\mathrm{P}_{\mathrm{c}}$ :

$$
P_{c}=\left(\frac{\gamma}{R_{p}}\right)\left(\frac{R_{1}}{R_{p}}\right)^{-1}
$$

where $\gamma$ is surface tension.

- $\mathrm{V}$, the volume of liquid in the film between two solids.

There are three conditions for film stability:

1) If the opposite liquid-gas surfaces touch or cross between two cylinders, the film breaks. In terms of the geometrical parameters defined in Figure 2, this condition for stability is $h>0$. This places an upper limit on capillary pressure, or, a lower limit on $\mathrm{V}$, for a stable film between cylinders a given distance apart.

2) Any candidate for a stable distribution of solids must clearly have equal forces acting in both directions on any given solid. Thus if $F_{1}$ draws adjacent cylinders $A$ and $B$ together, and $F_{2}$ draws $B$ to its other neighbor $C$, then the net force on cylinder $\mathrm{B}$, i.e., $\left(\mathrm{F}_{1}-\mathrm{F}_{2}\right)$, must be zero.

3) For cylinders placed an equal distance from each other, if $(\partial F / \partial Q)<0$, then a differential displacement of one cylinder away from one neighbor and towards the other results in an increase in force drawing the closer pair together and a decrease 


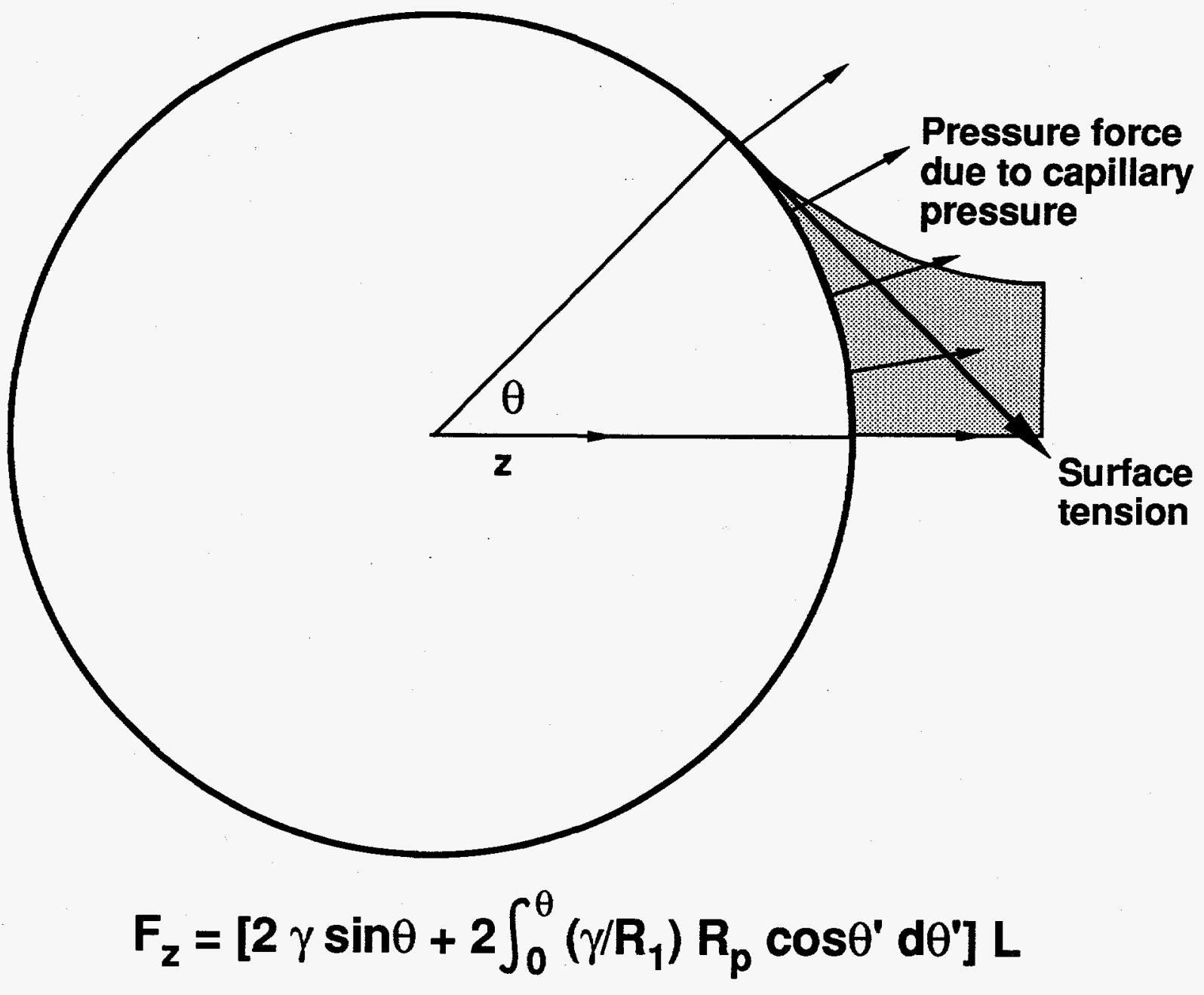

Fig. 3. Capillary force pulling two solid cylinders together 
in attraction between the other pair. For a film with many cylinders, this would result in clumping of cylinders together; a wide gap between one pair of cylinders would open up in which the opposite gas surfaces would touch, in violation of the first condition for stability above. Thus a condition for stability with initially equal spacing between cylinders is $(\partial \mathrm{F} / \partial \mathrm{Q})>0$.

For cylinders placed unequal distances apart, e.g., with $F_{1}$ and $Q_{1}$ between cylinders $\mathrm{A}$ and $\mathrm{B}$ and $\mathrm{F}_{2}$ and $\mathrm{Q}_{2}$ between cylinders $\mathrm{B}$ and $\mathrm{C}$, the corresponding condition for stability is

$$
\left(\frac{\partial \mathrm{F}}{\partial \mathrm{Q}}\right)_{1}+\left(\frac{\partial \mathrm{F}}{\partial \mathrm{Q}}\right)_{2}>0 .
$$

The partial derivative $(\partial F / \partial Q)$ can be evaluated at either constant capillary pressure, which is equivalent to carrying it out at constant $R_{1} / R_{p}$, or at constant volume of liquid in the films, i.e., constant $V$. Although in the artificial 2D geometry posed here liquid could not flow from between one pair of cylinders to another, our intention is to model in a simplified way the stability of 3D films stabilized by spheres, not cylinders. For such a film, liquid can freely move along the film in response to nonuniform capillary pressure. Therefore the condition of constant $R_{1} / R_{p}$ is probably more appropriate than constant $V$.

\section{RESULTS AND DISCUSSION}

\section{Experiments}

\section{Bubble Stabilization bv Solids in Synthetic Hanford Waste}

Upon cooling the samples, no precipitate was observed for EDTA concentrations below $0.1 \mathrm{M}$. The solid particles in the samples containing higher concentrations of EDTA, viewed by microscopy, appeared to be between 1 and $3.5 \mu \mathrm{m}$ in size. The few small, long-lived bubbles that were observed under the microscope all were completely covered by tiny crystals. These bubbles evidently were very long-lived, having survived in the synthetic waste for days or weeks. This suggests stabilization of the bubbles by solids. Upon sparging the waste with nitrogen, a thick froth was formed that, however, mostly 


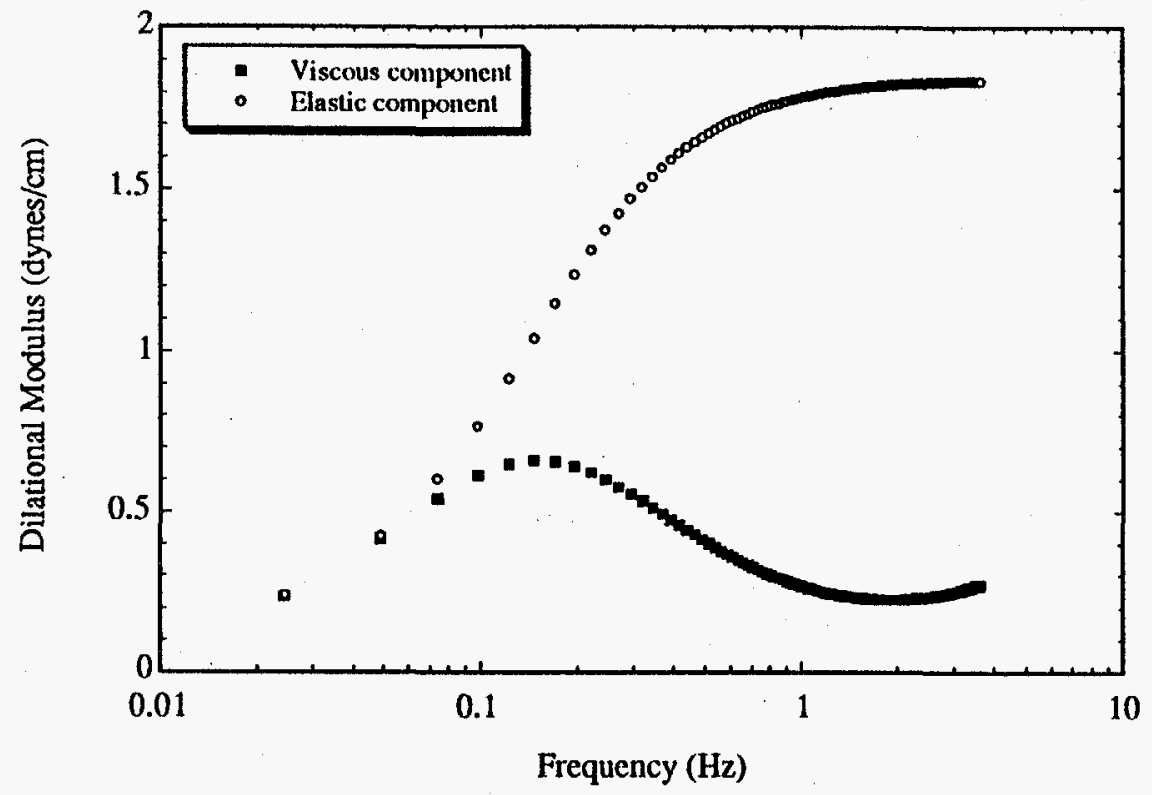

Fig. 4. Dilational properties of simulant-air interface containing no EDTA and with no solid particles deliberately added to the gas-liquid interface. 


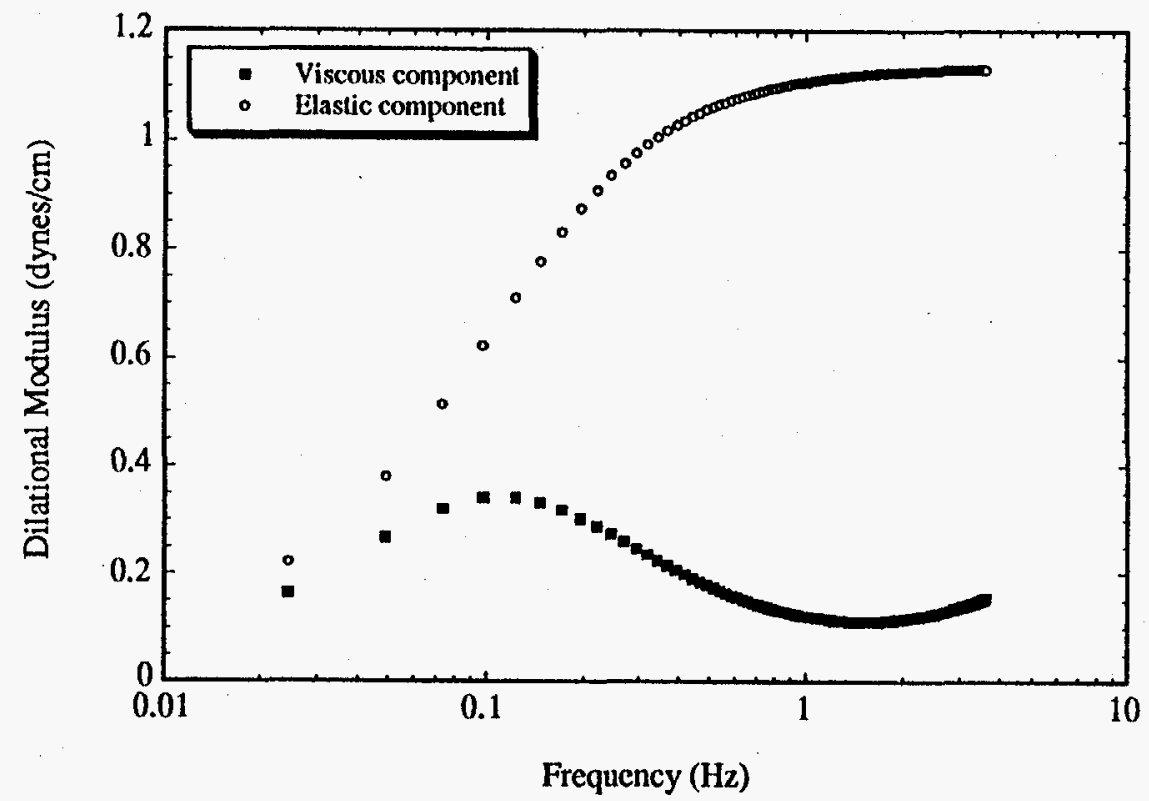

Fig. 5. Dilational properties of simulant-air interface containing 0.05M EDTA with no solid particles deliberately added to the interface. 


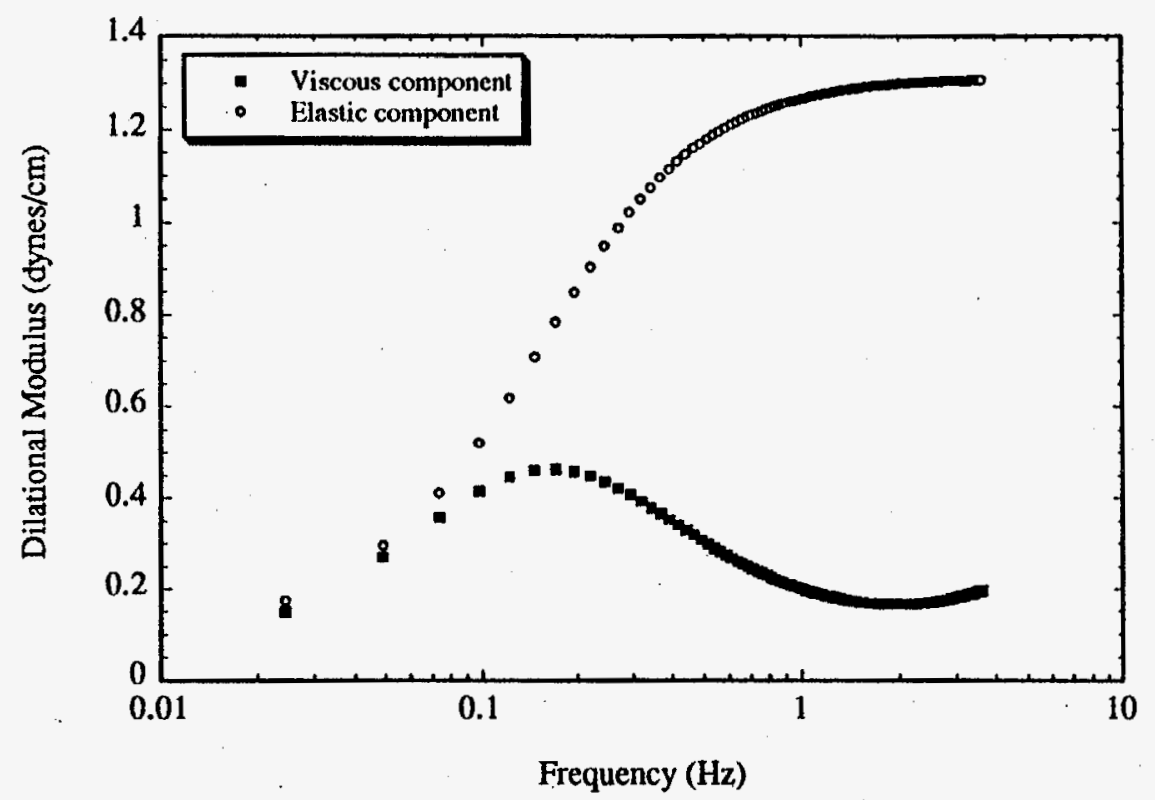

Fig. 6. Dilational properties of simulant-air interface containing 0.1M EDTA with no solid particles deliberately added to the interface. 
decayed within a few minutes upon stopping the flow of nitrogen. Bryan et al. (14) report longer-lived suspension of solids and formation of crusts in similar synthetic tank wastes. The reason of the difference is unclear, though there are some differences between the formulations; the range of concentrations of organics in our samples spans that in those of Bryan et al.

\section{Interfacial DilationaL Properties}

The dilational modulus for interfaces with no particles is shown in Figures 4-7, where they are plotted as a function of frequency. Similar plots for the interfaces containing particles are shown in Figures 8 and 9 . The frequency at which the viscous component goes through a maximum corresponds to the characteristic time constant of any relaxation mechanism at the interface. This may include diffusion along the interface (Marangoni effect) or diffusion to and from the bulk fluid to the interface, with the former expected to be much faster.

One of the important parameters of the frequency spectrum is the limiting elasticity, which is the asymptotic value of the elastic component as the frequency is increased. This is shown in Figure 10 as a function of EDTA concentration. It can be seen that when there are no solid particles at the interface, the limiting dilational elasticity tends to decrease with EDTA concentration. However, in the presence of particles there is a significant increase in the dilational elasticity, which also increases with EDTA concentration. A possible explanation for these observations is the increased hydrophobicity of the particle surface as the EDTA concentration is increased (14). In other words, there is increased attraction between the particles at the interface which makes it more difficult for the particles to move apart from one another as the area of the interface is increased.

The dilational viscosity corresponding to the characteristic relaxation frequency is shown in Figure 11. It can be seen that, although the dilational viscosity decreases with EDTA concentration, it is not significantly affected by the presence of solid particles at the 


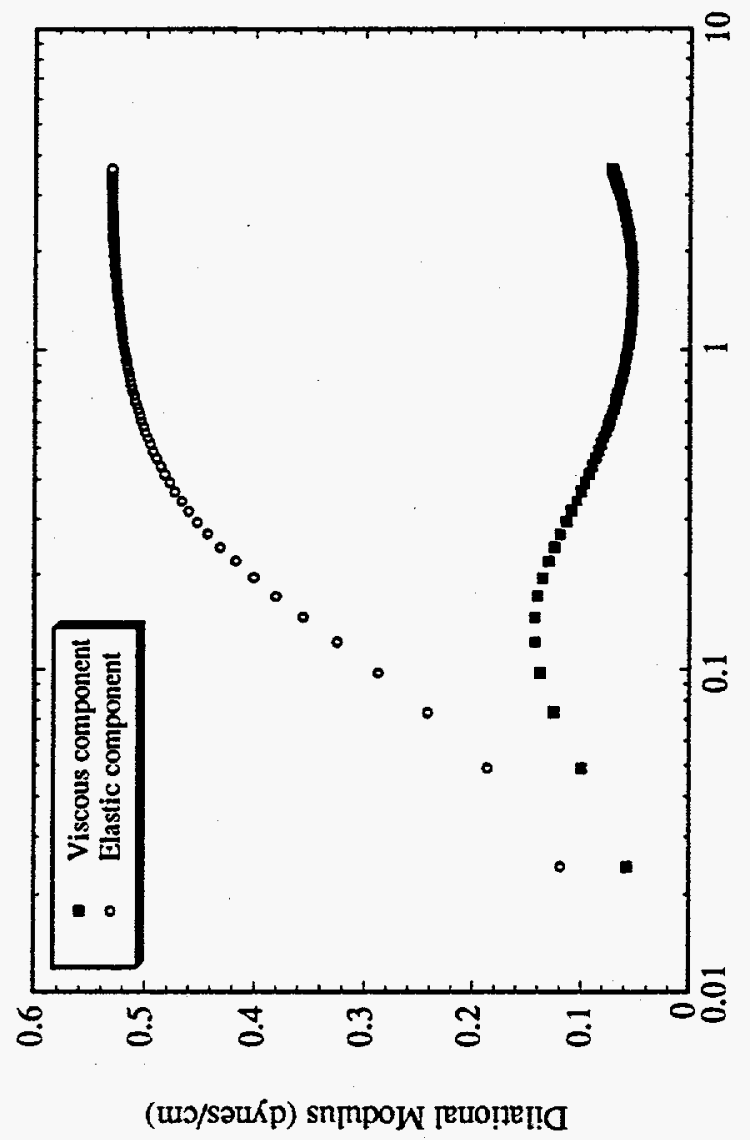

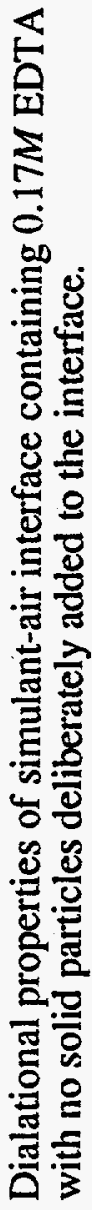

in 


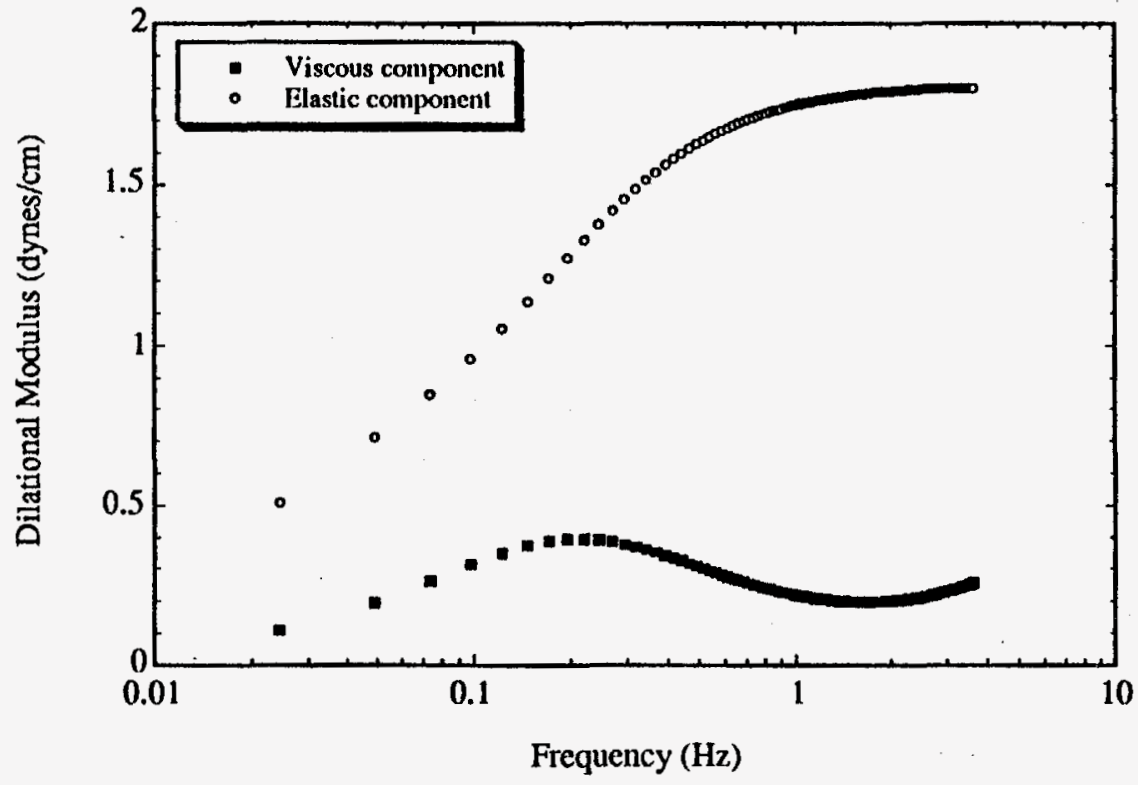

Fig. 8. Dilational properties of simulant-air interface containing 0.1 $M$ EDTA with solid particles deliberately added to the interface. 


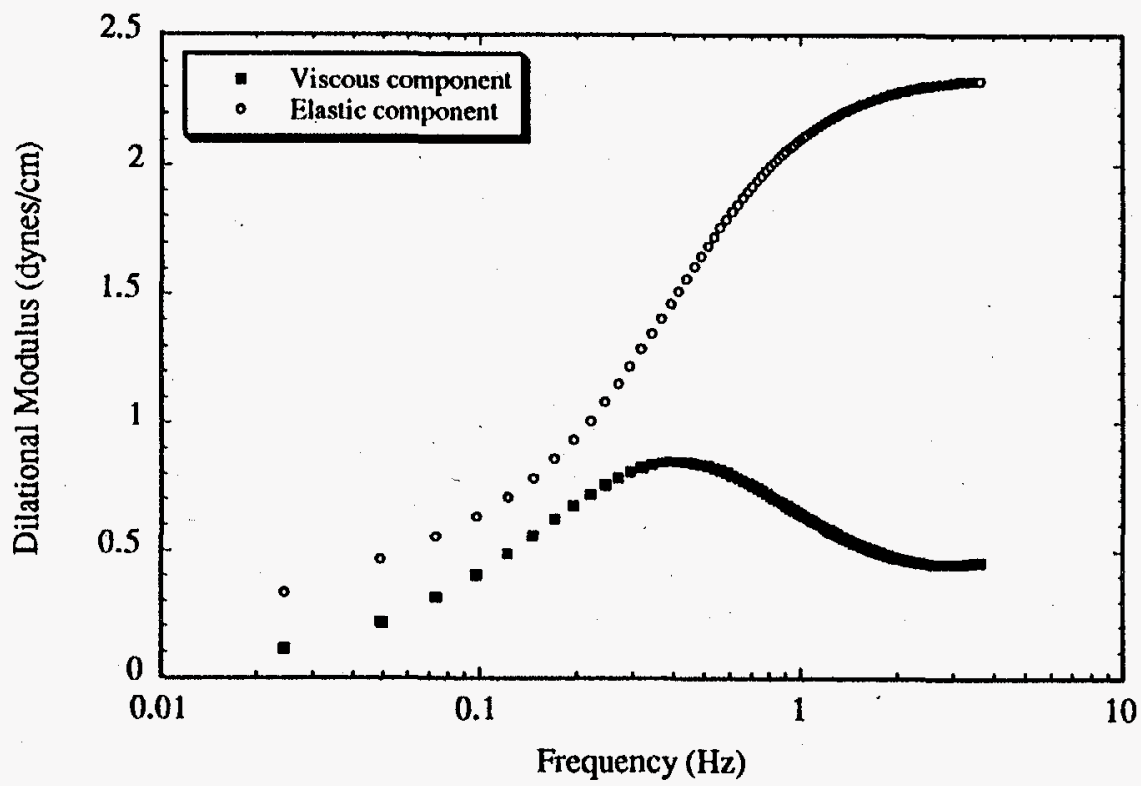

Fig. 9. Dilational properties of simulant-air interface containing 0.17M EDTA with solid particles deliberately added to the interface. 


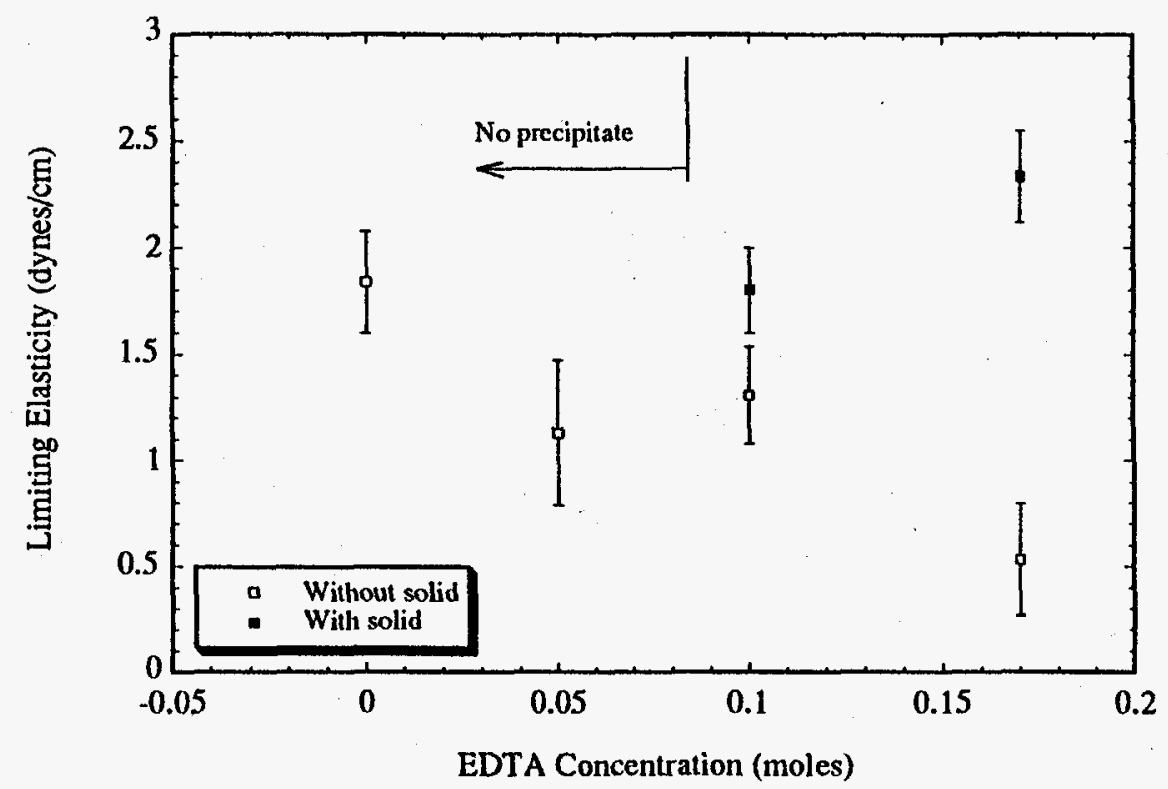

Fig. 10. Effect of EDTA concentration on the limiting values of dilational elasticity. The effect of solid particles that were introduced deliberately at the interface is quite pronounced. No solid precipitate was observed at EDTA concentrations less than $0.1 \mathrm{M}$. 


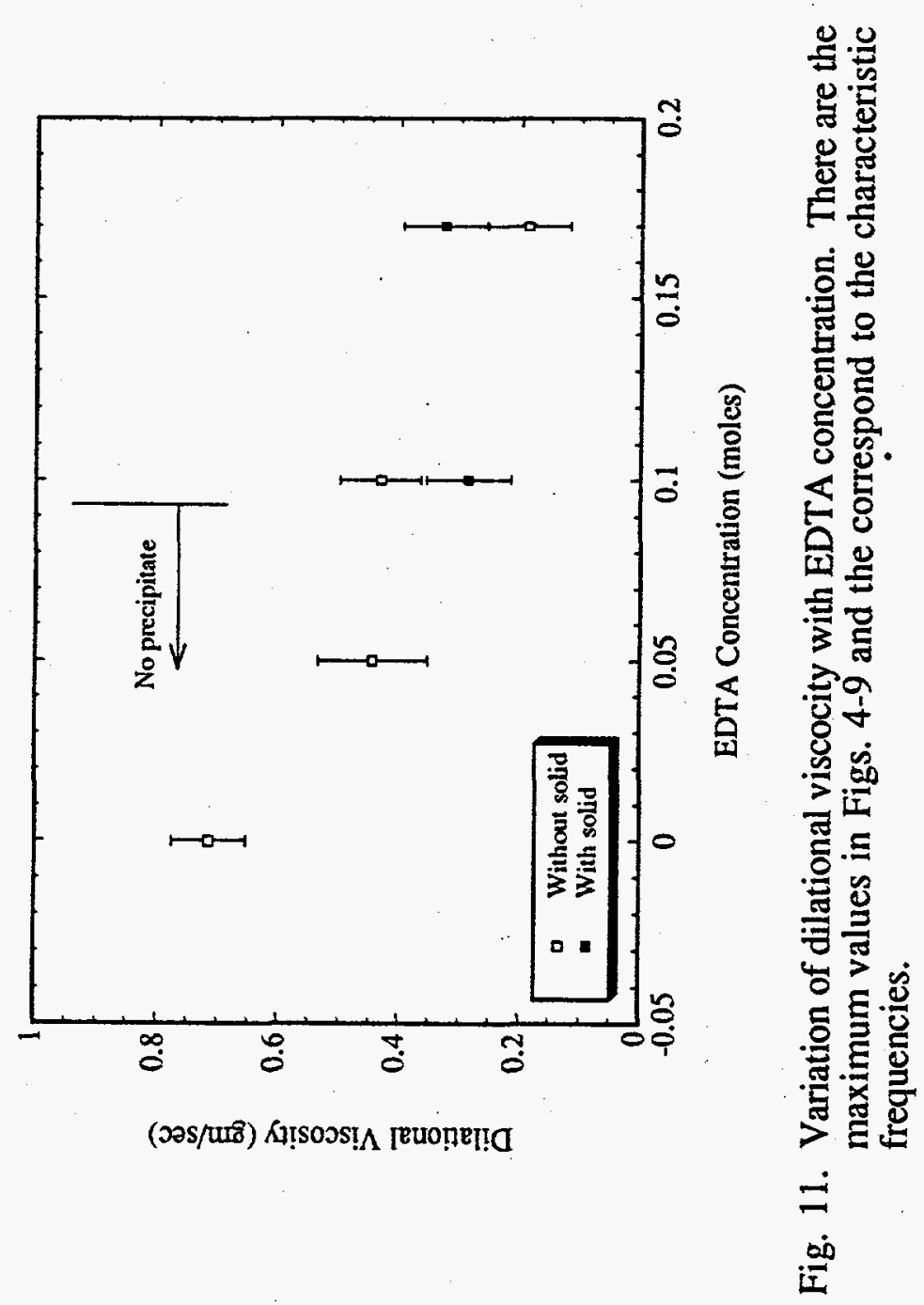


interface. Thus the viscous component is not expected to have much effect on the stability of the interface, in qualitative agreement with experimental results for systems containing carbon graphite particles at an oil-water interface (22).

The characteristic relaxation time is shown in Figure 12. It can be clearly seen that, while EDTA alone has practically no effect, the relaxation mechanisms tend to be faster in the presence of solid particles with increasing EDTA concentration. This may also be explained on the basis of increased hydrophobicity of the particle surface: i.e., the driving force for diffusion of these particles to the interface increases as they become less water wet. These observations, therefore, suggest that the viscoelastic behavior exhibited by the interface is predominantly due to diffusion of solids and not due to any reorientation process at the interface.

\section{Theory}

Figure 13a shows the limit of stability (condition $1: h>0$ ) for films in terms of $V$, i.e., the minimum liquid volume for stable liquid films between cylinders. Figure 13b shows the limit in terms of $R_{p} / R_{1}$; in effect, the maximum capillary pressure that films may support. Figure 13a shows that films with small, closely spaced solid particle can support substantial capillary pressures (large $R_{p} / R_{1}$ ). For instance, with $R_{1}=10 \mu \mathrm{m}, \gamma=90$ $\mathrm{mN} / \mathrm{m}$ and $\mathrm{R}_{\mathrm{p}} / \mathrm{R}_{1}=10, \mathrm{P}_{\mathrm{c}}=9 \times 10^{4} \mathrm{~Pa}$, or about $13 \mathrm{psi}$.

Figure 14 and 15 explore the limits of stability according to condition (3) for perfectly wetting liquid films $(\theta=0)$. Here the force $F$ between cylinders is made dimensionless by dividing by $(\gamma \mathrm{L})$, where $\mathrm{L}$ is the axial length of the cylinders. Films with fixed liquid volumes between the solids, whether or not the volume is equal between all solids, can be stable to clumping of the solids (Figure 14, region where $(\partial F / \partial \mathrm{Q})>0$ ). If, instead, capillary pressure is uniform along the film and liquid is free to redistribute itself, no films of the geometry explored here with a finite initial separation between the solids $(\mathrm{Q}>0)$ are stable (Figure 15: $(\partial \mathrm{F} / \partial \mathrm{Q})<0$ everywhere). However, if the solids in 


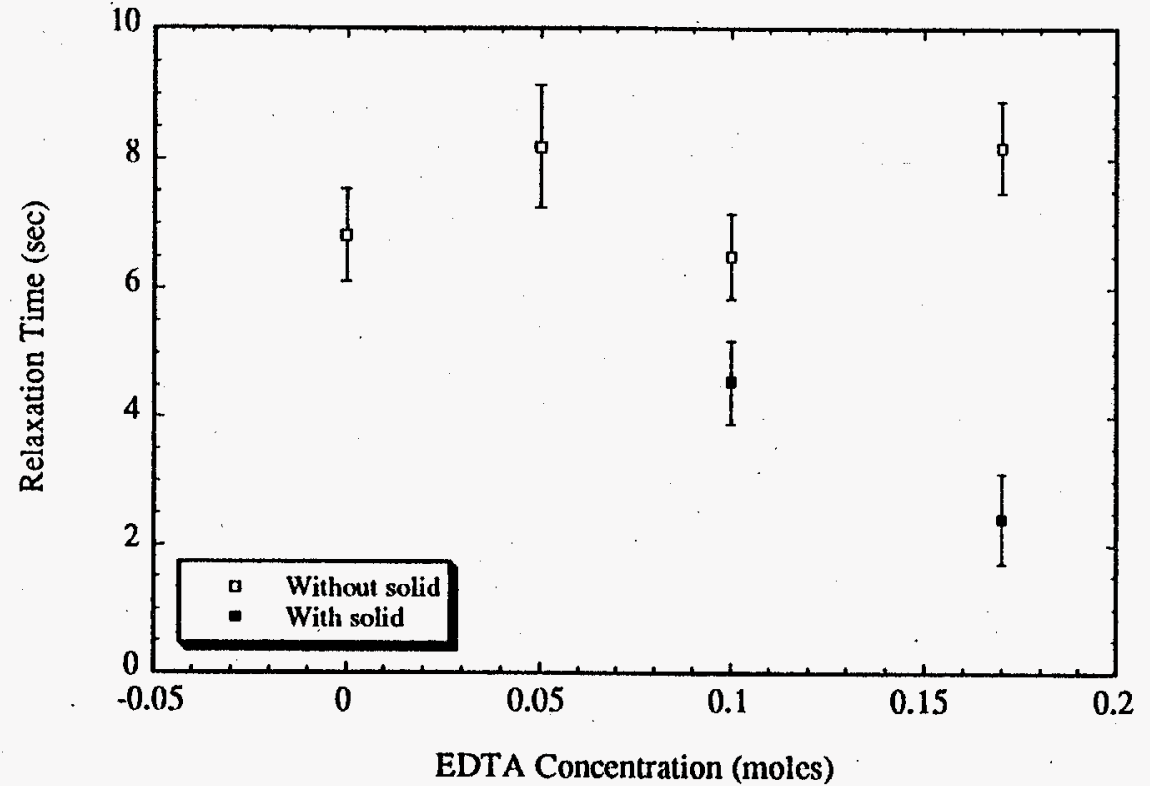

Fig. 12. Effect of EDTA concentration and presence of solid particles deliberately added to the interface on the characteristic relaxation time. 


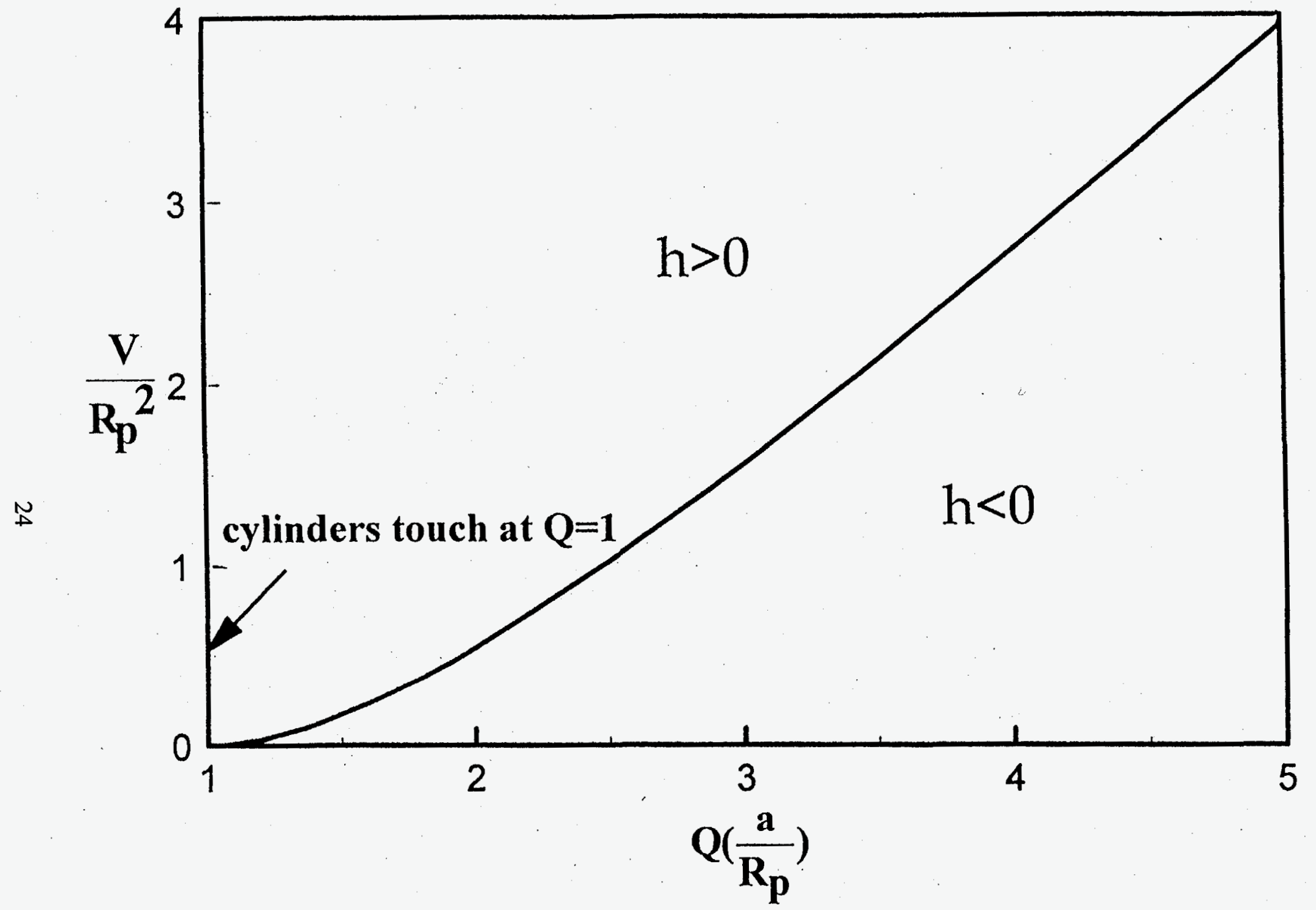

Fig. 13a. Limit of stability for films (Criterion 1) for $\theta=0$ 


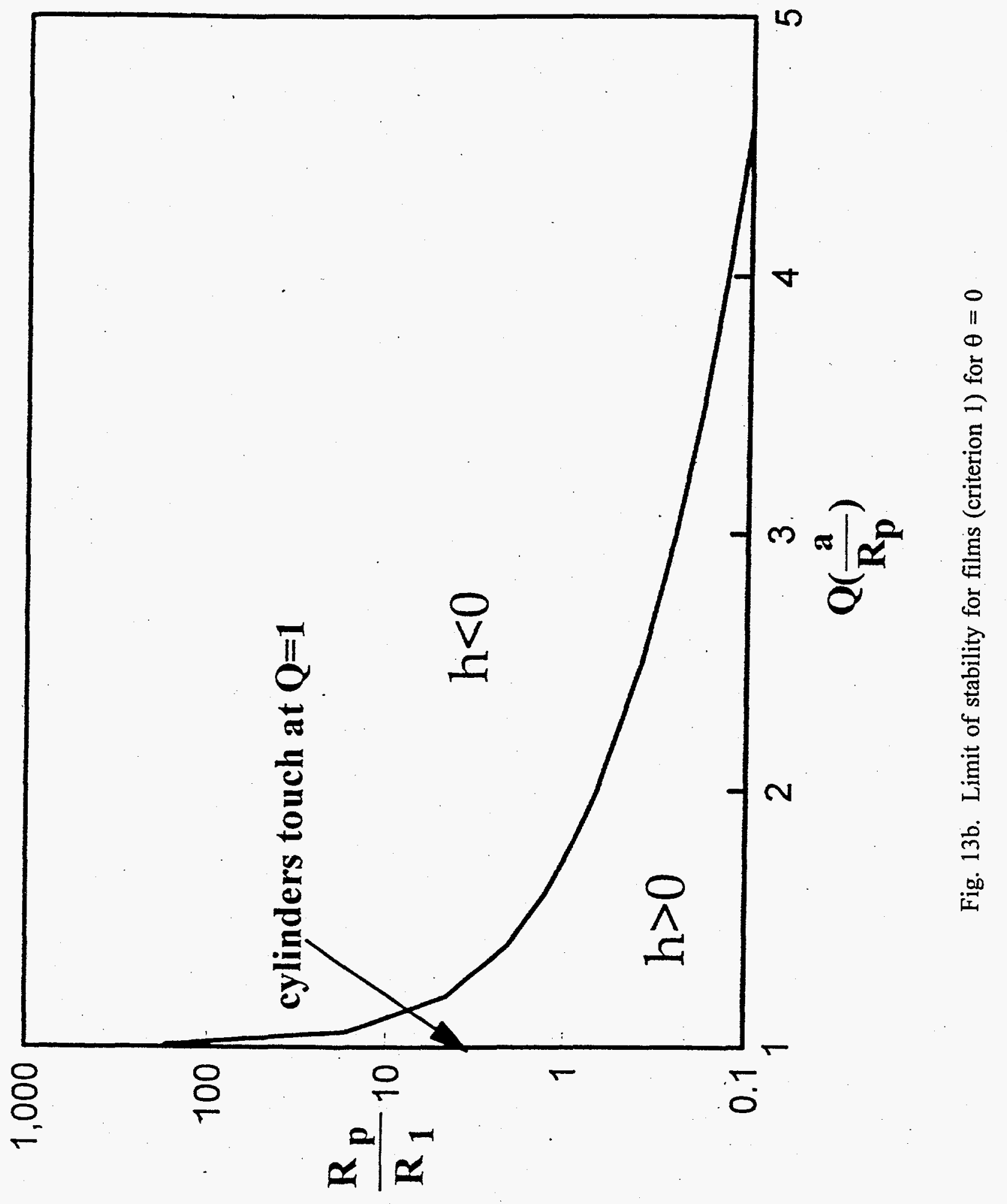




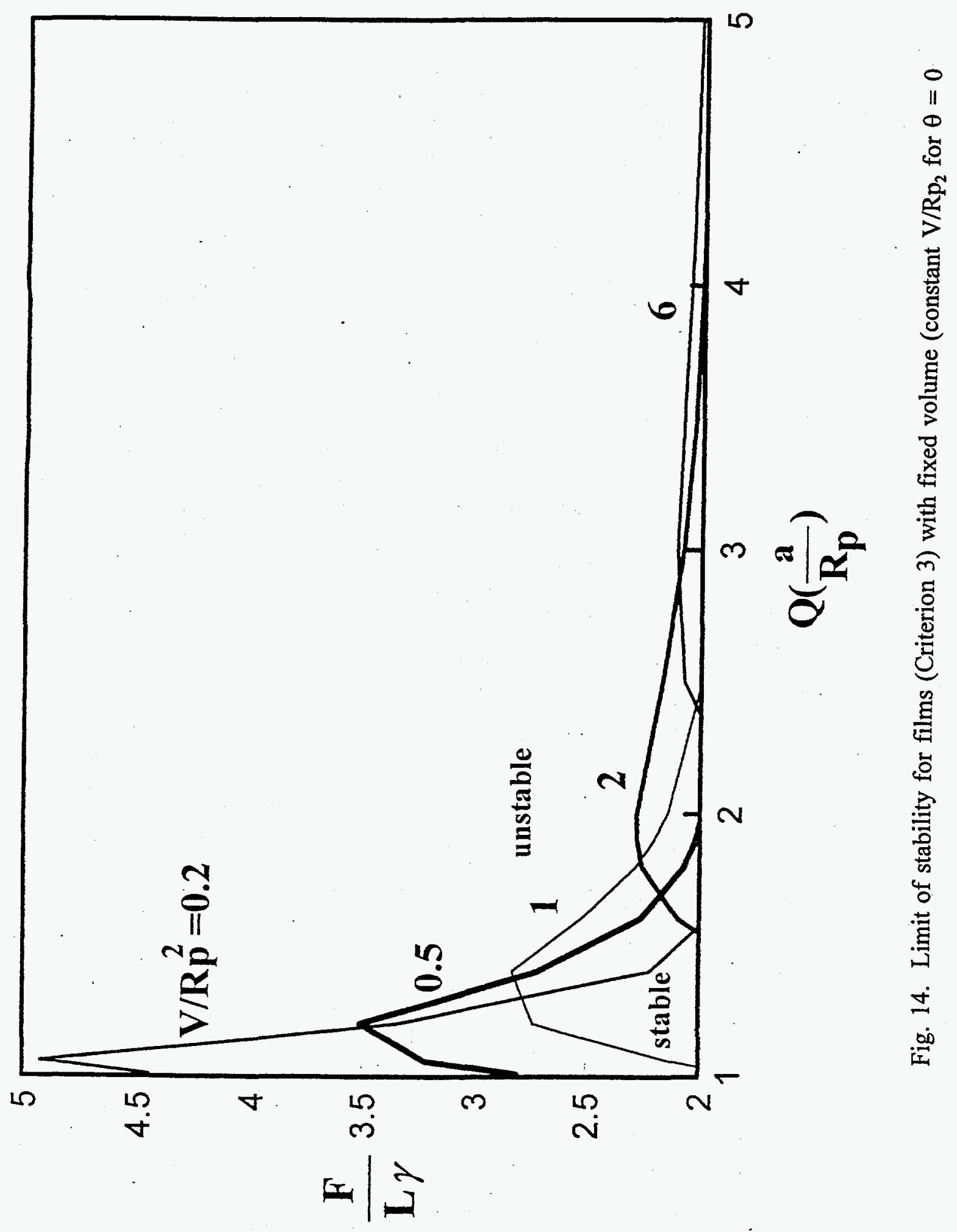




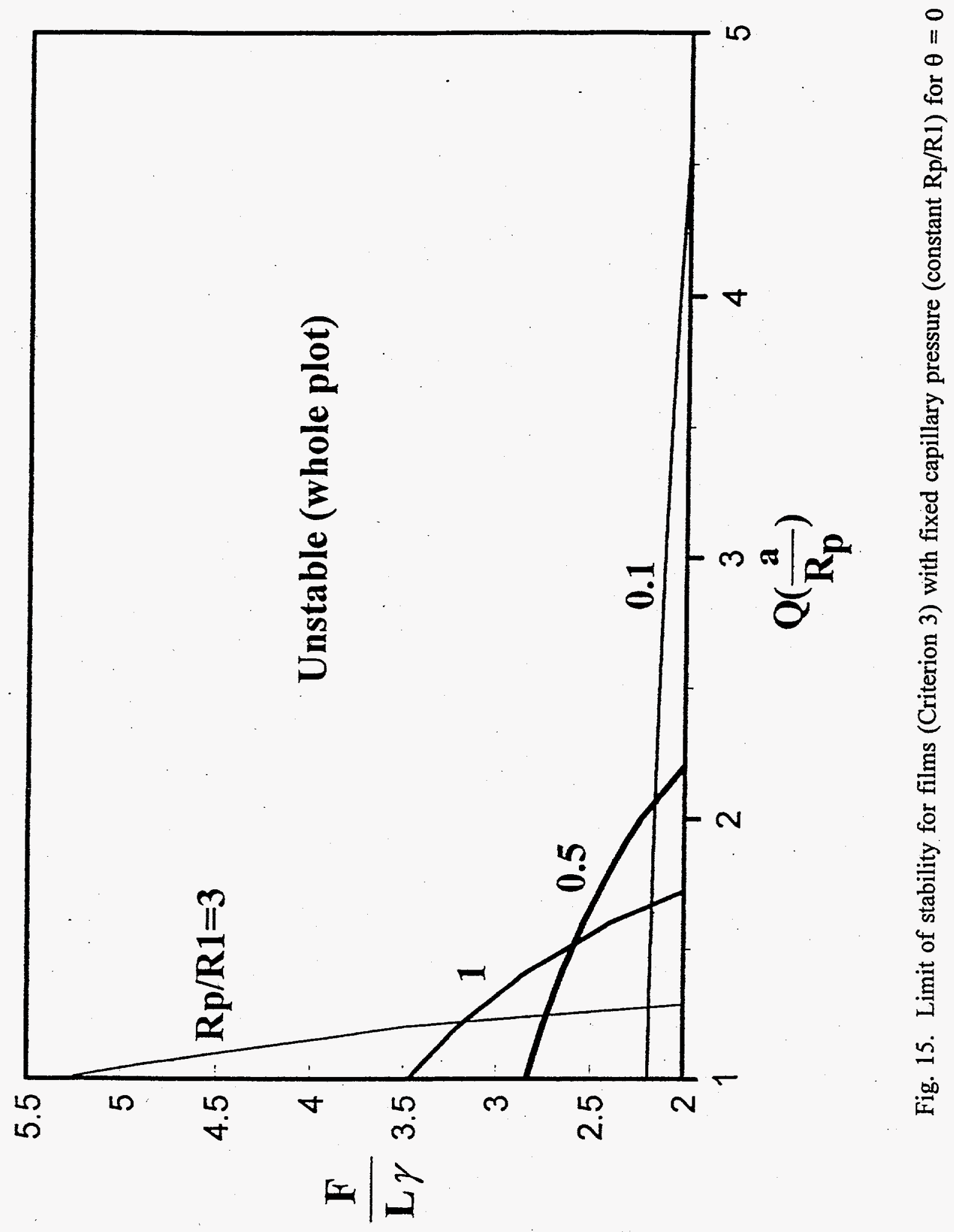


the film are touching $(Q=0)$, then the sort of clumping that can destabilize a film with $Q>$ 0 is prevented. This may begin explain why films that evolve slowly as bubbles approach each other in the sludge are stable, but films that stretch quickly during the rapid gas expansion after density inversion break: that is, if slow bubble expansion allows new film to be created with closely-packed solids, but rapid stretching requires the film to stretch with only the solids initially in place to stabilize it.

Figure 16 compares stability according to conditions 1 and 3 for films with fixed, equal volume $\mathrm{V}$ between solids. There is a substantial range of conditions in which a film would be stable $(h>0)$ if clumping were prevented, but a much-smaller range in which the film is stable to clumping $(\partial F / \partial Q>0)$. The boundaries of this region, estimated from the crude mesh in Figure 14, are only approximate.

Figures 17 through 20 repeat Figures 13 through 16 for contact angle $\theta=25^{\circ}$. Trends are similar, except that the range of conditions for film stability, both $h>0$ and $\partial \mathrm{F} / \partial \mathrm{Q}>0$, are greater for the larger value of $\theta$ ( $c f$. Figures 16 and 20 )..

It is likely that liquid films between bubbles are stabilized not by a single row of solid particles as envisioned in our simplified model but by a close-packed collection of solids many rows deep. An important additional issue is the stability of small armored bubbles to loss of mass by diffusion through surrounding liquid to larger bubbles. A crucial consideration in both cases is whether the solids stick to each other with finite yield stress or can roll and slide past each other freely. Modeling of such cases with the same sort of schematic 2D approach used here appears feasible.

\section{CONCLUSIONS}

1. Synthetic Hanford waste created here showed solids accumulation at surfaces and some stabilization of bubbles in a froth upon sparging.

2. Dilational interfacial rheological measurements indicate increasing hydrophobicity with increasing EDTA concentration in the wastes. There is greater dilational elasticity of 


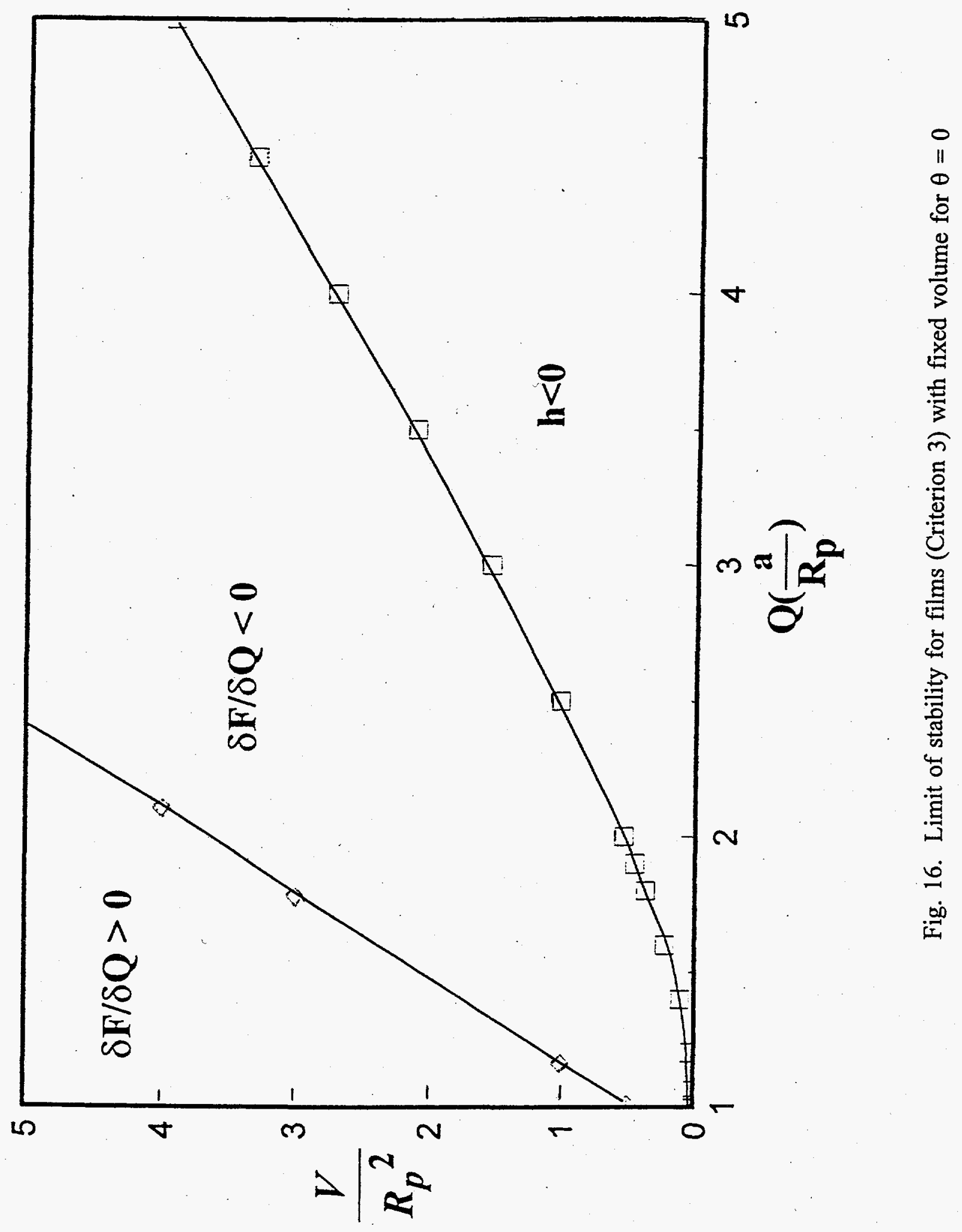




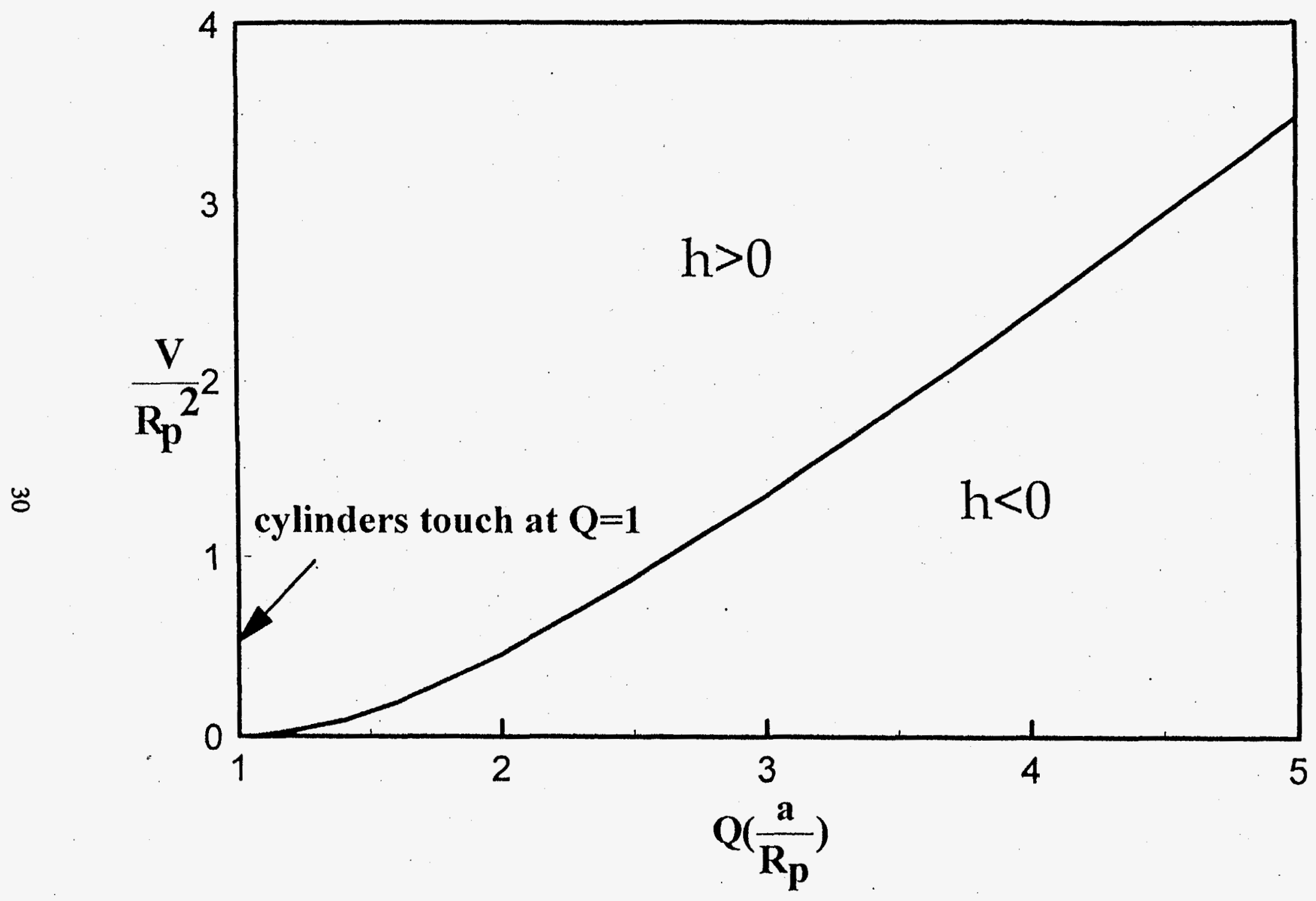

Fig. 17a. Limit of stability for films (Criterion 1) for $\theta=25$ 


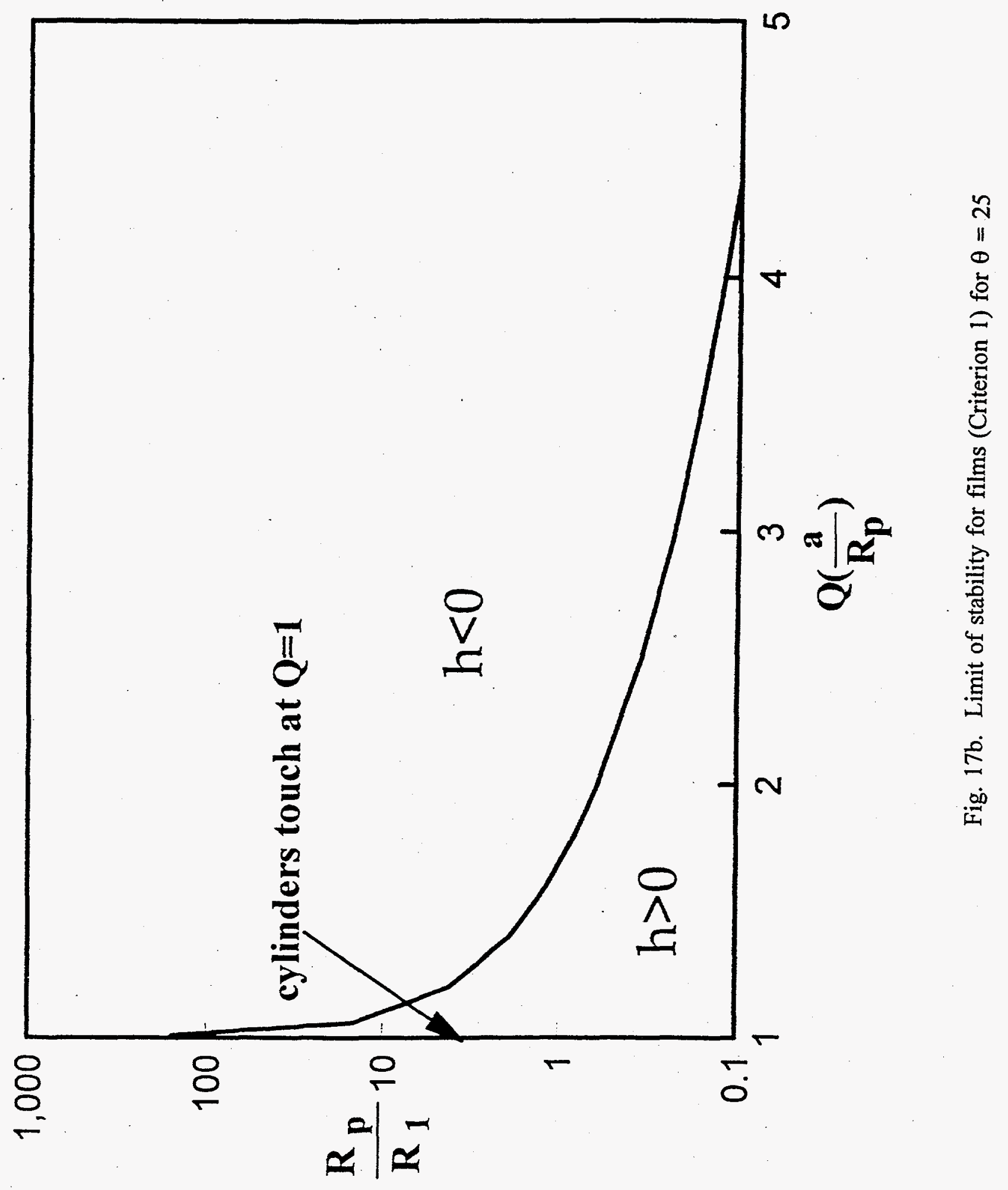




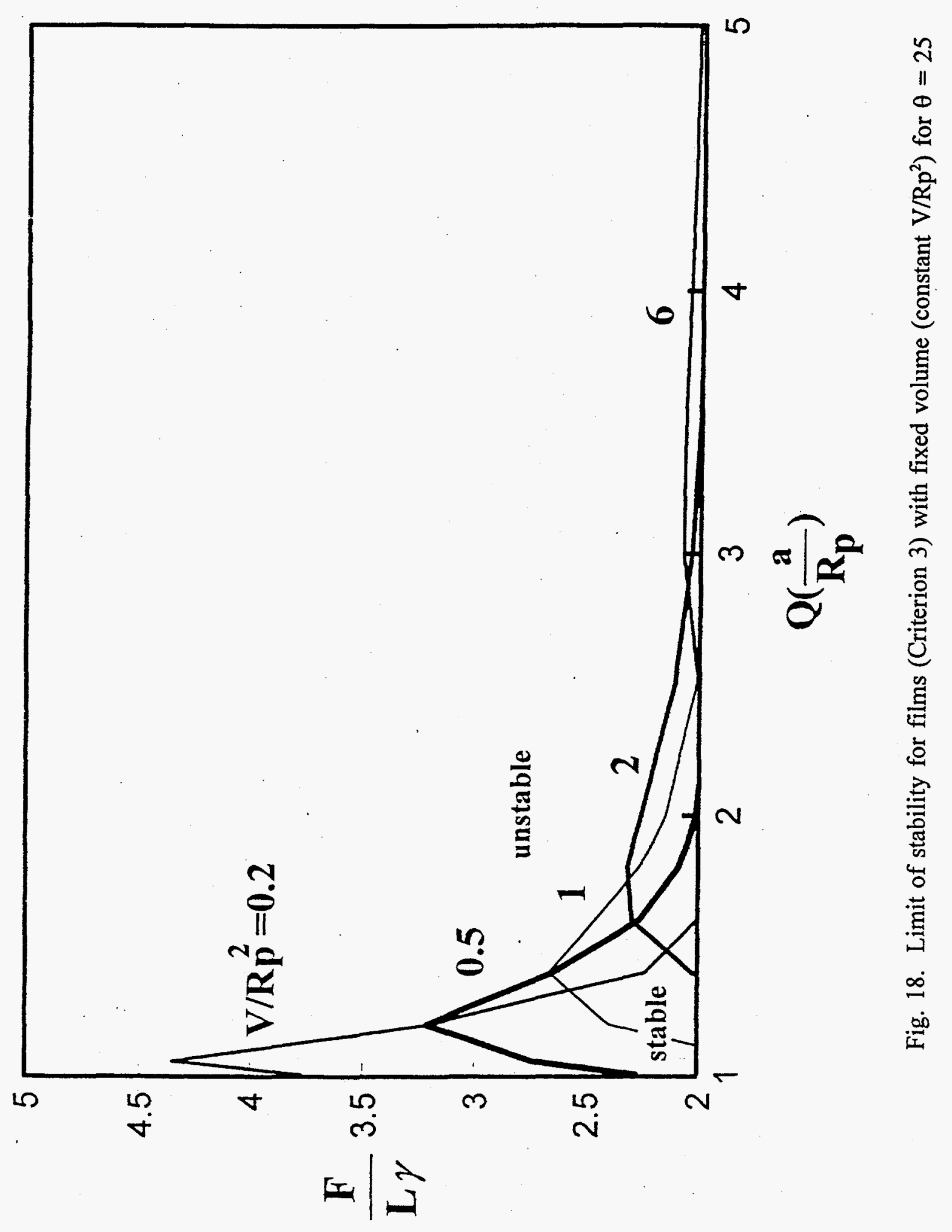




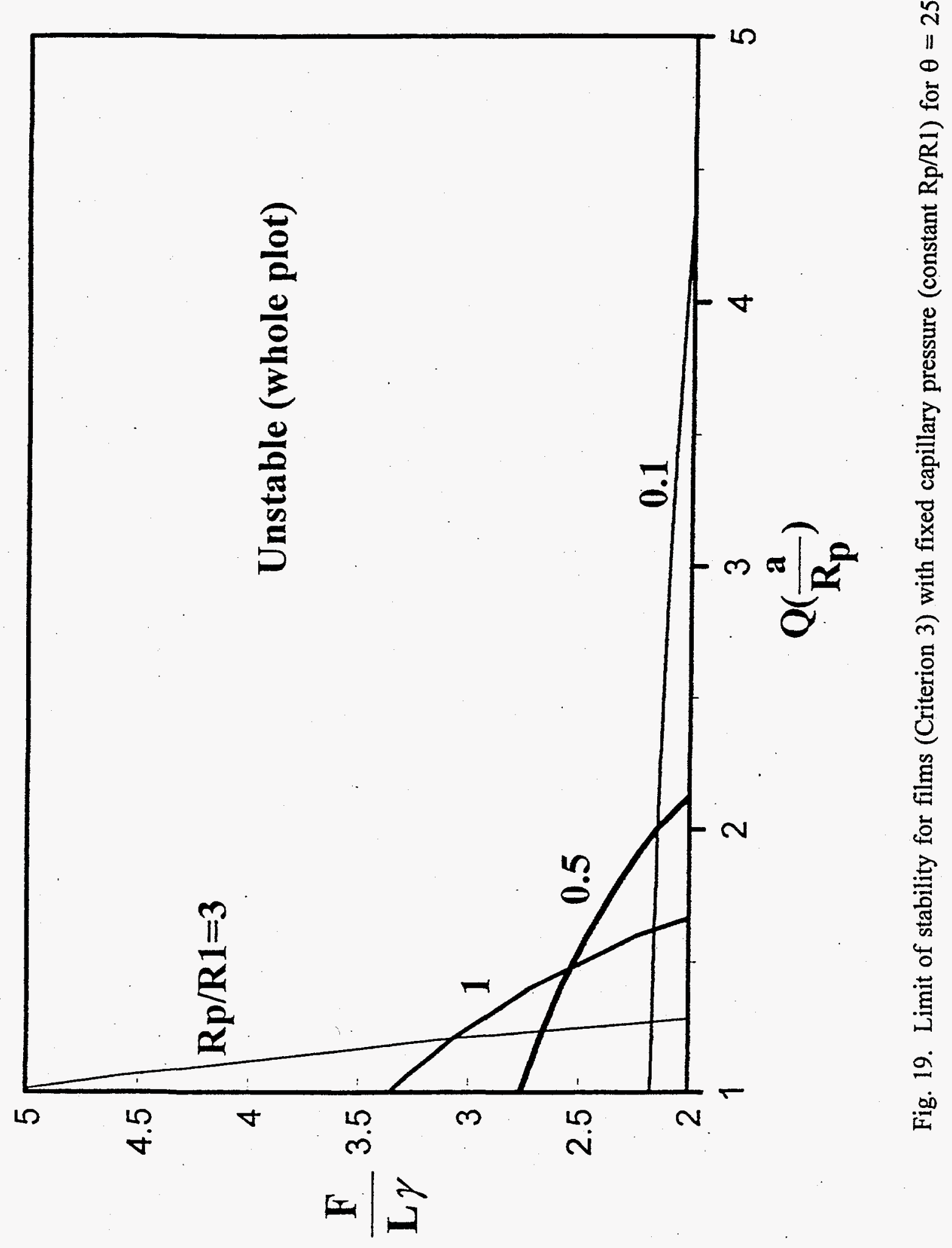




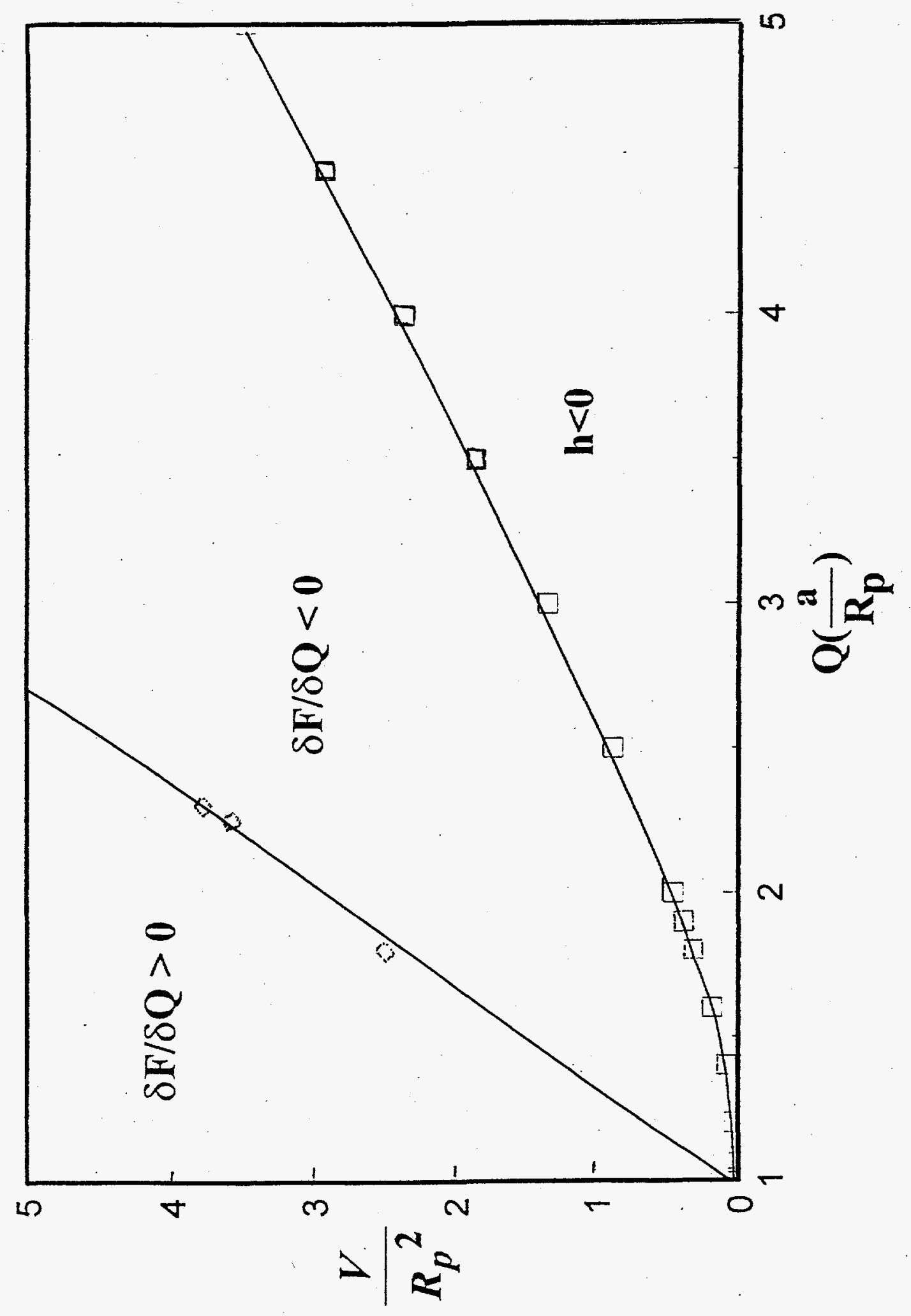

O) 
the interface with solid particles present on the interface.

3. Theoretical modeling of a 2D liquid film between bubbles containing one row of solid particles suggests that in 3D such a film would be unstable unless the solids all touch. This hints at a possible mechanism for bubble stabilization, if it can be argued that slowly evolving interfaces as bubbles grow toward each other in the sludge have solids closely packed, but that rapid expansion of gas during density inversion forces the films to expand without additional solids.

\section{REFERENCES}

1. Allemann, R. T., and T. M. Burke, D. A. Reynolds, and D. E. Simpson, 1993. "Assessment of Gas Accumulation and Retention - Tank 241-SY-101," WHC-EP0576, Westinghouse Hanford Company, Richland, Washington.

2. Gaudin, A. M., "Flotation," 2nd ed., McGraw-Hill, New York, 1957.

3. Pickering, S. U., J. Chem. Soc. 91, 2001 (1907).

4. Briggs, T. R., J. Ind. Eng. Chem. 13, 1008 (1921).

5. Finkle, P., Draper, H. D., and Hildebrand, J. H., J. Amer. Chem. Soc. 45, 2780 (1923).

6. Schulman, J. H. and Leja, J., Trans. Faraday Soc. 50, 598 (1954).

7. Lucassen-Reynders, E. H. and van den Tempel, M., J. Phys. Chem. 67, 731 (1962).

8. Tadros, T. F. and Vincent, B., in "Encyclopedia of Emulsion Technology," P. Becher (ed.), 129 (1983).

9. Gelot, A., Freisen, W., and Hamza, H. A., Colloid Surf. 12, 271 (1984).

10. Levine, S. and Sanford, E., Can. J. Chem. Eng. 58, 622 (1985).

11. Blair, C. M., Chem. Ind. 20, 538 (1960).

12. Menon, V. B. and Wasan, D. T., Sep. Sci. Technol. 23, 2131 (1988); Colloids Surf. 23, 353 (1987).

13. Bryan, S. A., Pederson, L. R., Ryan, J. L., Scheele, R. D., and Tingley, J. M., 
PNL-8169, Report prepared at the Pacific Northwest Laboratory for the U. S. Department of Energy, August, 1992.

14. Bryan, S. A., Pederson, L. R., and Scheele, R. D., Proc. Waste Management '92 Conference, Tucson, AZ, March, 1992, p. 829.

15. Zapryanov, Z., Malhotra, A., Aderangi, N., and Wasan, D. T. Int. J. Multiphase Flow 9, 105 (1983).

16. Callaghan, I. C. and Neustadter, E. L. Chem . and Ind. 17, 53 (1981).

17. Mukherjee, S. and Kushnick, A. P., in "Oilfield Chemistry," ACS series, 364 (1989).

18. Neustadter, E, Whittingham, K., and Graham, D., in "Surface Phenomena in Enhanced Oil Recovery," Shah, D. (ed.), 307 (1981).

19. Clint, J. H., Neustadter, E., and Jones, T., Dev. Petrol. Sci. 13, 135 (1981).

20. Eley, D. D., Hey, M. J., and Lee, M. A., Colloids and Surfaces 24, 173 (1987).

21. Loglio, G., Tesei, U., and Cini, R., J. Colloid Interface Sci. 71, 316 (1979).

22. Tambe, D. E., Ph.D. Dissertation, The University of Texas at Austin (1993).

23. Frye, G. C., and Berg, J. C., J. Colloid Interface Sci. 127, 222 (1989).

24. Levine, S., and Bowen, B. D., Colloids Surfaces A70, 33 (1993). 


\section{Distribution}

No. of

Copies

Offsite

2 Office of Scientific and

Technical Information

N. G. McDuffie

Civil Engineering Department

Apperson Hall 202

Oregon State University

Corvallis, OR 97331-2302

3 W. R. Rossen

Dept. of Petroleum/Geosystems

Engineering

The University of Texas at Austin

Austin, TX 78712-3246
No of

Copies

Onsite

1 DOE Richland Operations Office

G. W. Rosenwald

S7-54

2 Westinghouse Hanford Company

G. D. Johnson

S7-15

D. A. Reynolds

R2-11

13. Pacific Northwest Laboratory

P. R. Bredt

M. E. Brewster

J. W. Brothers (2)

P7-25

P. A. Gauglitz (3)

L. R. Pederson

S. D. Rassat

C. W. Stewart

Information Release (3)
K9-62

K9-20

P7-41

K2-44

P7-41

K7-15

K1-06

Distr.1 

-

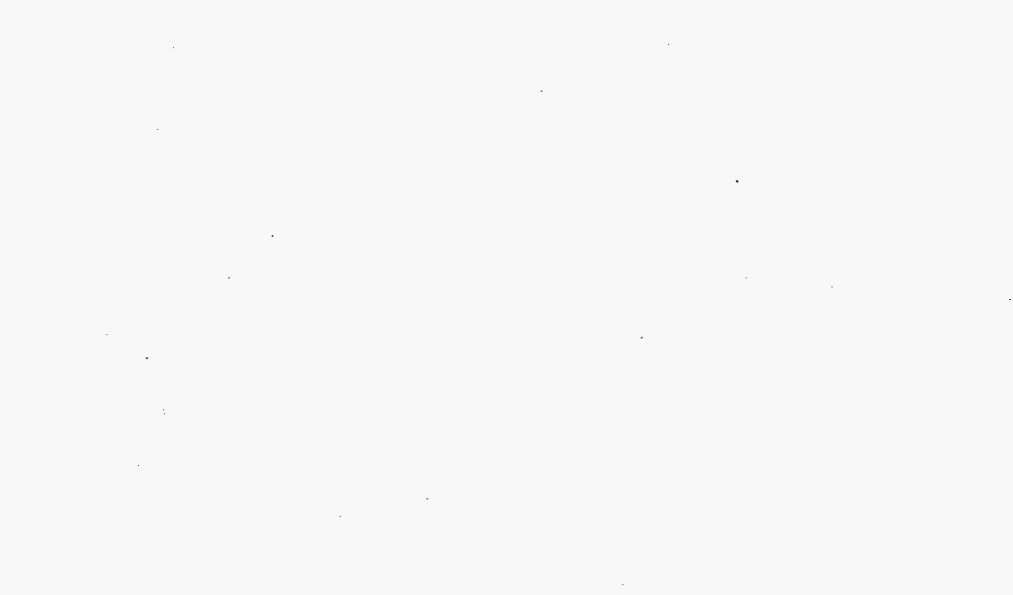

